\title{
Pilot-scale development of pressurized fixed-bed gasification for synthesis gas production from biomass residues
}

\author{
Esa Kurkela ${ }^{1}\left(\mathbb{D} \cdot\right.$ Minna Kurkela $^{1} \cdot$ Ilkka Hiltunen $^{1}$ \\ Received: 15 March 2021 / Revised: 26 April 2021 / Accepted: 27 April 2021 \\ (C) The Author(s) 2021
}

\begin{abstract}
Advanced transportation biofuels have been the focus of intensive development since the early 2000s, and gasification in combination with synthesis technologies represents a flexible production pathway to deliver fuels for heavy-duty transport sectors that are difficult to electrify. This article is related to the pilot-scale development of a process concept aiming to smaller-scale production plants than are feasible with fluidized-bed gasifiers. Five test weeks with a total gasification time of $347 \mathrm{~h}$ were realized at a pilot plant that consisted of the pressurized staged fixed-bed gasifier, raw gas cooling to $500-600{ }^{\circ} \mathrm{C}$, filtration with robust metal filters, and catalytic reforming of tars and methane. The gasifier combined an updraft primary stage and a catalytically enhanced secondary stage where most of the updraft tars were decomposed. The tar content of the product gas, $2-12 \mathrm{~g} / \mathrm{m}^{3}$, was of the same order of magnitude as determined previously for fluidized-bed gasifiers. Consequently, similar filtration and reforming methods could be successfully applied. After the reformer, the contents of $\mathrm{C}_{2}$-hydrocarbon gases and high-molecular-weight tars were negligible.
\end{abstract}

Keywords Gasification · Biomass · Fixed-bed $\cdot$ Updraft $\cdot$ Oxygen-blown $\cdot$ Syngas

\section{Introduction}

Advanced transportation biofuels have been intensively developed in Europe during the last two decades, and gasification in combination with synthesis technologies represents a flexible production pathway to deliver fuels, especially for heavy-duty transport sectors that are difficult to electrify. However, despite significant research and development resources, none of the developments has so far led to industrial deployment $[1,2]$. The attempt to reach a satisfactory economic situation by exploiting economies of scale leads to extremely large-scale plant concepts that are eventually considered too risky by investors. Large-scale plants cannot often be integrated to district heating of industrial steam production, as it is difficult to find large enough heat consumers.

All recent industrially developed gasification-based biomass-to-liquids (BTL) concepts have applied either

Esa Kurkela

esa.kurkela@vtt.fi

1 VTT Technical Research Centre of Finland Ltd, P.O. Box 1000, FI-02044 VTT Espoo, Finland entrained flow gasification of pre-treated biomass or fluidized-bed gasification followed by secondary treatment of tars and hydrocarbon gases [3]. These technologies are aiming at applications with more than 100 MW feedstock input, and both have some principal challenges that limit their utilization potential. Entrained-flow gasifiers are most suitable to feedstocks that can be easily pulverized, like coal, or are directly in a liquid form, such as black liquor [4]. Complicated pre-treatment by torrefaction or pyrolysis is needed for feeding inhomogeneous low-density biomass residues or wastederived feedstocks into entrained flow gasifiers $[5,6]$. Besides, the different ash behavior of various biomass qualities will create challenges for achieving stable molten ash removal from the high-temperature gasifier [7]. Steamoxygen-blown directly heated fluidized-bed gasifiers have limited carbon conversion and produce fly ash, which contains unreacted carbon and soot particles as well as contaminants originating from feedstock $[8,9]$. The feedstock reactivity and ash sintering behavior of different biomass qualities also vary in a wide range [10], which makes it challenging to reach high carbon conversion and to avoid bed agglomeration and deposit formation, especially with high-alkali biomass [11]. This technology was developed in 2007-2012 at a 0.5MW pilot plant [12] and demonstrated at a 12-MW scale in 
Finland for the large-scale conversion of wood residues to synthesis gas $[2,13]$. Despite a technically successful demonstration realized by NSE Biofuels Oy with their partners, the company decided in 2012 not to continue the development into a full-scale BTL unit in Finland [14]. This decision was based on the economic challenges of the first-of-a-kind plant and especially the estimated high investment cost of the planned production unit with ca. $400 \mathrm{MW}$ feed capacity.

In 2012, VTT started to study different alternatives to reduce the required scale of BTL plants, and since then this development has been carried out as part of national and European projects. This work has included VTT's development work on the front-end biomass gasification and gas cleaning process, and contacts and collaboration with developers of such synthesis technologies that can be applied at the target size range corresponding to 50-150 MW biomass input. Two different gasifier types have been developed and tested at the pilot-scale: low-pressure dual fluidized bed steam gasification [15] and pressurized staged fixed-bed gasification [16]. This paper is focused on the fixed-bed gasification alternative, which is aiming for $10-50 \mathrm{MW}$ feedstock capacities of the gasifier.

\section{Review of previous fixed-bed gasification developments}

Usually, fixed-bed biomass gasifiers are used to produce power for small-scale applications (downdraft gasifiers, below $1 \mathrm{MW}$ ) or to produce tar-containing gas (updraft, 1$10 \mathrm{MW}$ ), which cannot be cleaned for syngas applications $[17,18]$. Downdraft gasifiers can be used only with lumpy biomass qualities, which have a low ash content or high ash melting temperature. In the classical downdraft gasifier, efficient tar breakdown is achieved in the hot oxidation zone, throat, which has a significantly reduced cross-sectional area, through which all pyrolysis products have to pass [19]. A pioneering syngas development was realized in the USA by Solar Research Institute (SERI) in 1980-1985, when a prototype, high-pressure, oxygen-blown, downdraft gasifier was built and operated in Golden, CO [20]. The SERI gasifier was called a "stratified downdraft gasifier" and it did not have a central throat to restrict the flow of solids as in classical downdraft gasifiers. Air or oxygen was introduced through the top of the bed and was well mixed with the biomass throughout the reaction zone. The biomass moved from the top to the bottom of the reactor through the biomass feed zone, the flaming pyrolysis zone, the active char gasification zone, and the inactive char and ash zone [20]. Tar measurements at the 1 ton/day prototype plant showed that tar contents were higher than in standard downdraft gasifiers. The endothermic $\mathrm{H}_{2} \mathrm{O}$ and $\mathrm{CO}_{2}$ char gasification reactions seemed to quench the gas temperature down to below $900{ }^{\circ} \mathrm{C}$ in a fraction of a second. Thus, it was impossible to maintain a hot charcoal bed above $900{ }^{\circ} \mathrm{C}$ in this gasifier and therefore the charcoal bed was not very effective in tar cracking. The stratified downdraft gasifier had several challenges due to which it was not selected as the basis of the development described in this paper. The carbon losses are similar to ordinary downdraft gasifiers and the tar contents are higher. In addition, it may be difficult to maintain a stable reaction of oxygen under different conditions and to avoid explosive ignitions at the upper part of the gasifier during process disturbances.

The other basic fixed-bed gasifier type, the updraft (or counter-flow) gasifier, is a simple refractory-lined reactor, in which air or steam and oxygen are introduced to the bottom of the bed through a grate, and biomass is fed from the top. A high-temperature oxidation zone is created at the bottom, where the oxygen first comes into contact with the char, but the combustion gases immediately enter a zone of excess char, where $\mathrm{CO}_{2}$ and $\mathrm{H}_{2} \mathrm{O}$ are reduced to $\mathrm{CO}$ and $\mathrm{H}_{2}$ by the excess carbon. As the gases then rise to lower temperature zones, they meet the descending biomass and pyrolyze the mass in the temperature range of 200 to $500{ }^{\circ} \mathrm{C}$. Continuing to rise, they contact wet, incoming biomass and dry it. Due to the counter current flow of gas and biomass, the heat generated in the oxidation zone is efficiently utilized resulting in low raw gas temperatures. The main advantages of this reactor type are high chemical efficiency to gas and tar, high carbon conversion and fully oxidized ash removal, and the fact that the maximum temperature can be controlled by mixing steam or $\mathrm{CO}_{2}$ into the gasification air or $\mathrm{O}_{2}$ [21]. On the other hand, a wide variety of pyrolysis products, tars and oils, enter into the gas without thermal decomposition reactions making it very difficult to clean the gas for any other applications than closed-coupled combustion in a boiler or kiln [18]. This gasifier type has been widely used for making synthesis gas from coal, for example at the Sasol refinery in South Africa, where several Lurgi gasifiers have been supplying syngas for the Fischer-Tropsch synthesis [22]. At these plants, the condensable oils and other chemicals are scrubbed from the gas, which is possible in the case of coal, but would be very challenging with biomass, which has significantly higher volatile matter content than coal.

In Finland, an air-blown updraft gasifier with a product name Bioneer was developed in the early 1980s, and since then several commercial plants have been built and operated at small district heating boilers and drying kilns [23]. Thermal cracking of updraft gas was tested at the pilot scale in the late 1980s to produce a gas that could be scrubbed and used in gas engines. The tar content of an updraft gasifier could be reduced from the original $50-150 \mathrm{~g} / \mathrm{m}^{3}$ to a level of $2-3 \mathrm{~g} / \mathrm{m}^{3}$ when the outlet temperature of the cracker was higher than $900{ }^{\circ} \mathrm{C}$ [21]. These concentrations are presented at standard conditions (STP) defined as $101.325 \mathrm{kPa}$ and $273.15 \mathrm{~K}$, and hereafter all volumetric flow rates and concentrations are 
normalized to standard conditions. However, a significant amount of soot was formed in partial combustion of the raw gas, and carbon deposits were formed on the surfaces of ceramic balls that were used to stabilize the operation of the cracker. Furthermore, the residual level of tars was still too high for the target application, and it was concluded that the required tar decomposition could not be achieved without catalysts [24]. A similar conclusion was, in essence, also made in the development of the stratified downdraft gasifier in the USA [20].

The development of fixed-bed gasification technology was started again in the late 1990s and now the main aim was to develop a $0.5-5 \mathrm{MW}_{\mathrm{e}}$ combined heat and power production system based on gas engines. The so-called novel gasifier was developed first at a 1-MW pilot plant at VTT and then a 5MW district heating plant was realized at Kokemäki [23]. The novel gasifier was a staged fixed-bed gasifier, where the bottom of the reactor was identical to the Bioneer updraft gasifier and the upper part was used as a thermal oxidation and cracking zone. The secondary air was introduced into the upper part of the gasifier through several vertically located nozzle zones and the temperature of the gas was gradually raised to 750 $850^{\circ} \mathrm{C}$. The pilot plant could be operated with low tar contents (3-5 $\mathrm{g} / \mathrm{m}^{3}$ tars and $4-5 \mathrm{~g} / \mathrm{m}^{3}$ benzene) and this gas could be effectively cleaned in the secondary catalytic reformer without soot formation problems. At the 5-MW demonstration plant, satisfactory operation could also be achieved but soot formation decreased the reformer activity and deposits were built on the front surfaces of the monolith catalyst layers. Evidently, this was caused by an overly intensive partial combustion taking place already in the gasifier and the empty gas space before the first catalyst layer, since the air was now preheated to $>700{ }^{\circ} \mathrm{C}$ and the air feeding to the secondary zone was realized with only one level of nozzles.

The gasifier described in this paper, now called the staged fixed-bed gasifier (SXB), is VTT's third fixed-bed gasifier design, which relies on the updraft principle as the primary conversion method. This gasifier is a combination of the updraft gasification already applied in the Bioneer gasifier and the second catalytic step integrated within the gasifier. The research is part of the development of the hybrid process called FlexCHX, which combines the use of renewable electricity and biomass gasification in the production of transport fuels and district heat. This paper is focused on the detailed experiences and performance of the gasifier, while the overall FlexCHX concept is described in [12], the pilot tests are briefly outlined in [25] and more detailed results for the development of the catalytic reformer are presented in [26]. The SXB gasifier is designed for pressurized operation as the aim is to produce synthesis gas for Fischer-Tropsch (FT) or other synthesis processes which operate at elevated pressure. In an industrial-scale FlexCHX process, the SXB gasifier and the subsequent gas cleaning units are planned to be operated at
0.5-1 MPa pressure and the resulting gas is then compressed to the target pressure of the synthesis unit. A special feature of the FlexCHX process is that the gasifier and the reformer are planned to be operated flexibly with different mixtures of oxygen, steam, and carbon dioxide [12]. When $\mathrm{CO}_{2}$ separated from the syngas is recycled back to the gasification process to replace part of steam, the water gas shift reaction pushes the gas composition towards higher $\mathrm{CO}$ contents and makes room for feeding additional electrolysis hydrogen to the syngas.

\section{Experimental}

\subsection{Pilot plant description}

The schematic of the SXB gasification pilot plant connected to the slipstream final gas cleaning unit and the bench-scale Fischer-Tropsch (FT) unit MOBSU (Mobile Synthesis Unit) is shown in Fig. 1. The pilot plant itself consists of the following main units: biomass feeding system, gasifier, raw gas cooler, filter unit, catalytic reformer, second gas cooler, pressure let down valve, district heating boiler. A slipstream of reformed and cooled gas is taken and introduced to the final gas cleaning train and compressed to $2.5 \mathrm{MPa}$ and led into the FT-synthesis unit. A general description of the pilot plant is given in [25] and the reformer is described in detail in [26]. In the following, the design and operation principles of the gasifier are described in more detail than in these previous publications.

Biomass is pressurized in two feed hoppers, which have a rotating device at the bottom to assist stable feeding by screw feeders. The upper hopper is used to pressurize the feedstock from atmospheric pressure to the gasifier pressure and inert the feedstock with nitrogen. This hopper is used periodically to load a biomass batch of $80-120 \mathrm{~kg}$ into the lower feeding hopper, which is always operated at the gasification pressure. The fuel feed rate is controlled by changing the rotation speed of the metering screw located inside the lower feeding hopper. Fuel is fed to the top of the primary gasification stage, and the feed rate is adjusted so that a stable bed level is maintained in the primary gasification stage. Overfeeding is avoided by following the moment of the slowly rotating mechanical level sensor located close to the top of the primary stage. The location of the most important temperature measurements of the gasifier is also shown in Fig. 1. This reactor was designed according to the principle presented in [27] and it was operated before the tests of this project as an air-blown gasifier to produce fuel gas. The reactor is a refractory-lined pressure vessel with an outer diameter of $1.62 \mathrm{~m}$ and an inner reactor diameter of $0.8 \mathrm{~m}$. The height of the inner reactor space of the primary stage is $1.7 \mathrm{~m}$ and that of the second stage $2.3 \mathrm{~m}$. In most of the tests, the primary and secondary stages were separated by a $30-\mathrm{mm}$-thick steel plate, which had four holes each 


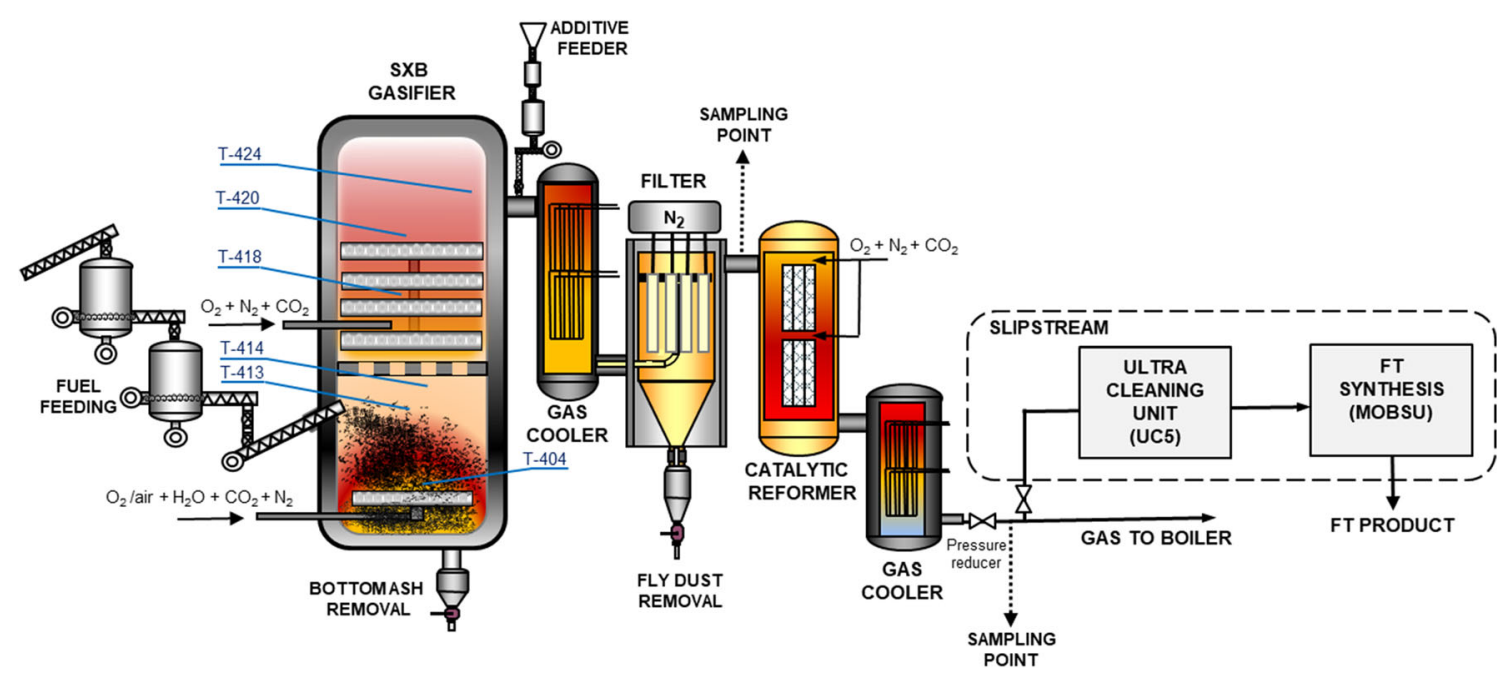

Fig. 1 Schematic of pressurized staged fixed-bed (SXB) gasification pilot plant

$40 \mathrm{~mm}$ in diameter. The raw gas from the lower updraft bed flew through the holes of the division plate into the secondary gasification zone and met directly the first distributor level of the secondary stage feed gases. These holes were later equipped with venturi-type inlet distributors, and it was possible to feed a small amount of air to the center of the venturi tubes. This was found to be useful in order to avoid the formation of tar deposits that could have gradually blocked the distributor holes. The last test run was carried out with a larger central opening of $0.4 \times 0.4 \mathrm{~m}^{2}$, as the aim was to examine whether the division plate has a strong effect on the performance of the secondary zone.

The primary gasification stage is operated as an ordinary counter-current reactor. Biomass feeding point is located in the middle of the gasifier below the division plate so that an updraft bed is created from the biomass char and ash at the bottom of the reactor. Primary gasification agents, mixtures of $\mathrm{O}_{2}$, air, steam, and/or $\mathrm{CO}_{2}$, are fed through a distributor to the bottom of the bed, where oxidation and gasification reactions take place. The bed of the primary stage is agitated by a grate, which is periodically rotated. The tar-containing updraft gas produced in the primary stage flow to the second stage of the gasifier, where secondary gasification gases are introduced through a catalytic distributor system. The gas temperature is raised from 300 to $600{ }^{\circ} \mathrm{C}$ to $750-870{ }^{\circ} \mathrm{C}$ by partial combustion reactions. Most of the updraft tars and oils are oxidized, reformed, or cracked in the second stage, resulting in a gas composition similar to that of fluidized-bed gasifiers.

The realization of the secondary zone was a compromise of achieving a good catalyst-gas contact and avoiding the fouling of catalyst surfaces and the whole structure by dust and soot. In the previously developed novel gasifier [23], raw gas from the secondary thermal cracking zone of the gasifier was led into a separate reformer vessel, where nickel monolith catalysts were used. Under certain operating conditions, this structure turned out to be too tight and dust or soot deposits were formed on the front surfaces of the monoliths despite the very low dust content of the raw gas. Consequently, a different design was chosen for the secondary stage of the SXB gasifier. The aim was to realize the invention described in [28], so that that the oxygen of the secondary gasification agent reacts within the catalyst layer and not in the open gas space around the catalyst element. This is considered beneficial to avoid similar soot formation problems that were met in the thermal cracking tests carried out with updraft gasifier in the 1980s [21] as well as in reforming of the gas from the novel gasifier [23].

The secondary feed gas, a mixture of $\mathrm{O}_{2}$ and $\mathrm{CO}_{2}$ or $\mathrm{N}_{2}$, is introduced to the secondary gasifier stage through a distributor

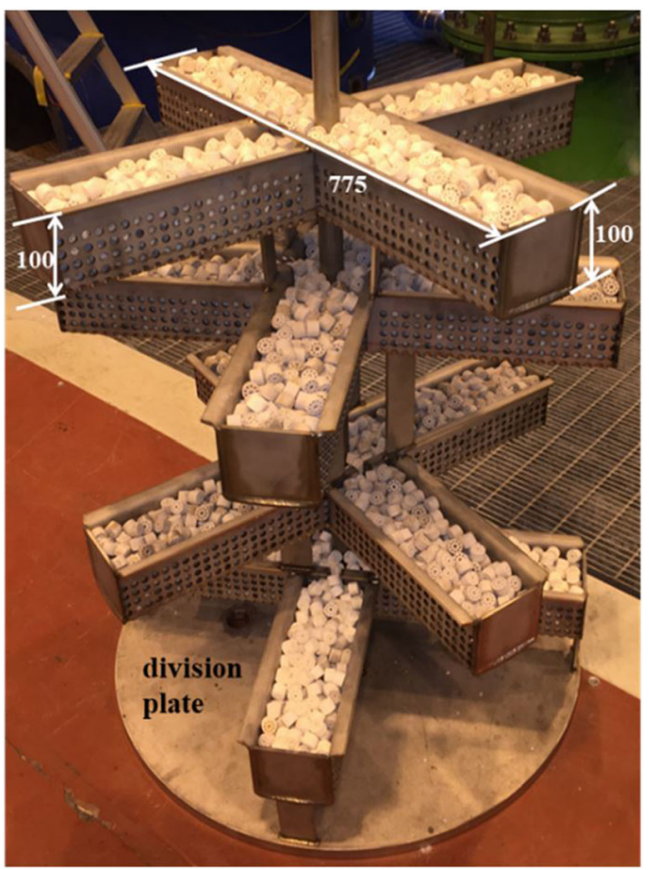

Fig. 2 A photograph and the key dimensions of the distribution system of secondary gasification agents 
system, which has four vertical levels as illustrated in Fig. 2. This photograph was taken during loading of the baskets with the catalyst particles. The secondary gasification gases are mixed and led to the central perforated tube, which is covered by catalyst particles and supported by a basket structure, which is made of perforated heat-resistant steel plate to allow the interaction of raw gas and gasification agents. The horizontal catalyst baskets are assembled at four vertical levels, each having four catalyst wings. Thus, there are a total of 16 catalyst wings. The length of the baskets is $0.775 \mathrm{~m}$, leaving ca. $10 \mathrm{~mm}$ between the basket endplate and the refractory wall of the gasifier. Each basket is $100 \mathrm{~mm}$ high and the heights of the bottom of the baskets measured from the distributor plate are $10 \mathrm{~cm}, 30 \mathrm{~cm}, 60 \mathrm{~cm}$, and $80 \mathrm{~cm}$. Consequently, the total height of the secondary gasification distributor system is $90 \mathrm{~cm}$, and the height of the free space above the last basket level is $1.4 \mathrm{~m}$. The baskets were loaded with $50 / 50 \%$ mixtures of two different ring-shaped particles. Cerium-lanthanum doped zirconia oxide catalysts prepared at VTT and commercial rhodium-based noble metal catalysts. A 10-hole ring calcium aluminate carrier $(19 \times 16 \mathrm{~mm})$ was used for both catalyst types.

After leaving the gasifier, the raw gas is cooled to 500 $600{ }^{\circ} \mathrm{C}$ followed by filtration and catalytic reforming. Then, the syngas is cooled to ca. $300{ }^{\circ} \mathrm{C}$ and the pressure is reduced close to the ambient pressure. The main part of the produced synthesis gas is combusted in the hot water furnace, which is connected to the district heating network of the City of Espoo. A slipstream of the gas is taken for the bench-scale ultracleaning and gas compression unit which is supplying clean syngas for the Fischer-Tropsch (FT) unit MOBSU.

The hot filter is the same as was used previously with the pressurized fluidized-bed experiments [29]. The same set of 12 one-meter-long ceramic candle filters were also used in the first test run, but then the ceramic elements were replaced by novel sintered metal elements supplied by GKN Sinter Metals Filters from Germany. These metal filters were previously tested in the laboratory and at VTT's dual fluidizedbed gasification pilot plant, and they seem to tolerate high operation temperature and sulfur-containing raw gases well [30]. The elements used at the SXB pilot plant were $1.108 \mathrm{~m}$ long and the total filtration surface area with 12 elements was $2.17 \mathrm{~m}^{2}$. Fine dolomite or magnesium oxide was fed to the top of the raw gas cooler to create a suitable dust cake, as the raw gas of the SXB gasifier had a very low initial dust content. The combination of low dust content and high tar content is problematic for filtration, as the tars and soot may build up into a sticky cake that cannot be removed by pulse cleaning [31]. At industrial plants, filter ash could be recycled in order to reduce the consumption of additives and to reduce the produced fly ash.

The catalytic reformer was a fixed-bed reactor, which had two stages. The required heat for the endothermic reforming reactions is provided by combustion reactions. Mixtures of $\mathrm{O}_{2}, \mathrm{~N}_{2}$, and $\mathrm{CO}_{2}$ are fed to both reformer stages. In the pilot test campaigns, different catalysts were tested as described in [26]. In the test campaign of 2019 , the same commercial nickel-based steam reforming catalysts were used as in the previous fluidized-bed tests [12]. In the tests carried out in 2020, novel precious metal catalysts of Johnson Matthey were utilized in both reformer beds. In the 2020 test runs, a slipstream of the syngas was further cleaned from sulfur compounds, trace halides, ammonia, and $\mathrm{HCN}$, as well as residual tars and benzene. The slipstream system consisted of a water scrubber, several sorbent beds, and gas compression to 2.5 MPa. This final gas cleaning system was previously used in connection to steam-blown fluidized-bed gasification described in [32]. Finally, the synthesis gas was led to the Fischer-Tropsch unit, which was operated in all tests in 2020. The results of the final gas cleaning and FT synthesis will be published separately.

The pilot gasification plant has two main sampling points for collecting sample gas for online gas analyzers, Micro GC and for the sampling of tars, nitrogen, and sulfur species. Similar sampling probes and collection methods were used as described in the pressurized fluidized bed tests of [33]. The first sampling point is located after the filter, and the second is located after the pressure let-down valve (Fig. 1). The product gas composition was measured from these sampling points with online gas analyzers (ABB AO2020) as well as with micro GCs (Varian CP-4900 equipped with a TC detector), which sampled every $15 \mathrm{~min}$. The continuous gas analyzers were used for monitoring the process stability during the experiments, and they measured the $\mathrm{CO}, \mathrm{CO}_{2}, \mathrm{H}_{2}$, $\mathrm{CH}_{4}$, and $\mathrm{O}_{2}$ contents in the dried product gas. The micro GCs were used for analyzing $\mathrm{CO}, \mathrm{CO}_{2}, \mathrm{H}_{2}, \mathrm{CH}_{4}, \mathrm{O}_{2}, \mathrm{~N}_{2}$, and $\mathrm{C}_{2}-\mathrm{C}_{5}$ hydrocarbons. Tars were measured according to the European Tar Protocol [34], and samples were taken in isopropanol. The samples were analyzed for benzene and 52 tar compounds up to coronene. Also, the water content was analyzed from the tar samples. The applied analytical methods are described in more detail in a previous paper [32].

\subsection{Feedstocks used in the pilot tests}

Five different biomass feedstocks were used in the pilot test runs representing different wood-based and agriculturalderived feedstocks. The clean wood pellets (WP) and bark pellets (BP) were made from sawmill residues, sawdust, and bark from softwood (spruce and pine) from eastern Finland. The forest residues (FRW) were also originally collected from eastern Finland and during pelletizing ca. 3\% kaolin was added to reduce the ash sintering tendency. Wood chips (WCH) originated from Lithuania and sunflower husk pellets (SFP) from Ukraine, and they were supplied by the Lithuanian project partners. 


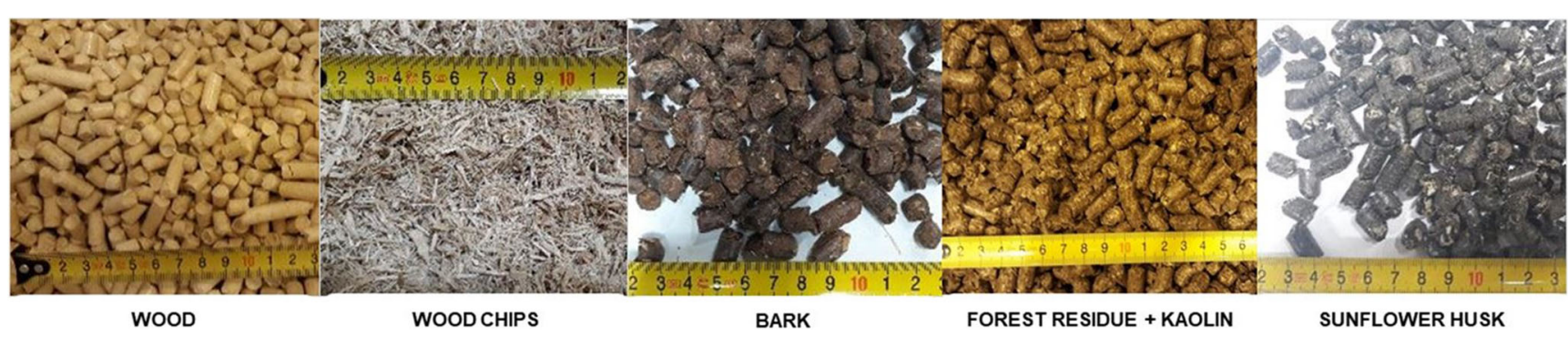

Fig. 3 Photographs of the feedstocks

Photographs of the feedstocks are presented in Fig. 3. Pelletized feedstocks were used in most of the tests for homogeneous quality, easy handling properties, and to guarantee stable and constant feeding. One test run period was carried out with un-pelletized wood chips, which had to be crushed to below $10 \mathrm{~mm}$ to achieve stable feeding in the small feeding screws. In commercial units, larger feedstock particles such as ordinary wood chips would be preferred, similarly to the commercial Bioneer gasifiers [23].

Table 1 Average analyses for the feedstocks used in the gasification experiments

\begin{tabular}{|c|c|c|c|c|c|}
\hline Feedstock & WP & $\mathrm{WCH}$ & $\mathrm{BP}$ & $\mathrm{FRW}+\mathrm{K}$ & SFP \\
\hline LHV, MJ/kg, dry basis (db) & 18.4 & 18.1 & 18.5 & 19.3 & 18.4 \\
\hline Moisture, wt\% & 7.4 & 10.0 & 9.4 & 7.5 & 10.3 \\
\hline \multicolumn{6}{|l|}{ Proximate analysis, wt $\%(\mathrm{db})$} \\
\hline Volatile matter & 82.5 & 85.7 & 72.3 & 75.6 & 75.0 \\
\hline Fixed carbon & 17.1 & 13.9 & 23.7 & 19.3 & 22.2 \\
\hline Ash, wt $\%$ & 0.4 & 0.4 & 4.0 & 5.1 & 2.8 \\
\hline \multicolumn{6}{|l|}{ Ultimate analysis, wt\% (db) } \\
\hline $\mathrm{C}$ & 49.8 & 48.6 & 50.9 & 49.6 & 52.1 \\
\hline $\mathrm{H}$ & 6.3 & 6.5 & 6.0 & 5.7 & 5.8 \\
\hline $\mathrm{N}$ & 0.13 & 0.1 & 0.5 & 0.4 & 0.7 \\
\hline $\mathrm{S}$ & 0.01 & 0.01 & 0.03 & 0.03 & 0.14 \\
\hline $\mathrm{O}$ (as difference) & 43.4 & 44.4 & 38.6 & 39.3 & 38.6 \\
\hline Ash & 0.4 & 0.4 & 4.0 & 5.1 & 2.8 \\
\hline \multicolumn{6}{|l|}{ Composition of ash, $\mathrm{g} / \mathrm{kg}$} \\
\hline $\mathrm{Si}$ & 17 & nd & 34 & 149 & 5.5 \\
\hline $\mathrm{Al}$ & 4.0 & nd & 13 & 99.7 & 1.3 \\
\hline $\mathrm{Fe}$ & 48 & nd & 9 & 19.5 & 3.6 \\
\hline $\mathrm{Ca}$ & 380 & nd & 265 & 142 & 130 \\
\hline $\mathrm{Mg}$ & 17 & nd & 32 & 13.6 & 77 \\
\hline $\mathrm{K}$ & 90 & nd & 67 & 34.1 & 360 \\
\hline $\mathrm{Na}$ & nd & nd & 3.6 & 8.3 & 13 \\
\hline $\mathrm{Ti}$ & nd & nd & 0.6 & 2.9 & 0.2 \\
\hline $\mathrm{S}$ & 14 & nd & 7.9 & 5.1 & 48 \\
\hline
\end{tabular}

$d b$, dry basis; $n d$, not determined; $W P$, wood pellets; $W C H$, crushed wood chips; $B P$, bark pellets; $F R W+K$, pelletized forest residues and kaolin; $S F P$, sunflower husk pellets
The average results for the proximate and ultimate analyses of the feedstocks used in the SXB tests are presented in Table 1. Wood pellets and chips represent clean wood with very low contents of ash, sulfur, and nitrogen. The ash, sulfur, and nitrogen contents of bark and forest residues were already higher, while the sunflower husk represented a typical agricultural residue with significantly higher contents of nitrogen, ash, and sulfur. In this gasification process, sulfur content has a strong effect on the reformer performance and it must also be taken into account in planning sulfur removal systems for industrial-scale units.

The ash compositions were determined by inductively coupled plasma mass spectrometry (ICP-MS) from samples, which were ashed at $550{ }^{\circ} \mathrm{C}$, and the results are also shown in Table 1 . The ashes of wood-based feedstocks have high calcium contents and moderate potassium contents, while the potassium content of the sunflower husk is very high. The addition of kaolin is visible in the aluminum and silica contents of forest residues. The effect of kaolin addition was not necessary in the case of FRW, but it was considered useful to check the effect of this additive on the gasifier performance, as it may be needed in the gasification of straw and other highalkali residues, for example.

\subsection{Test runs and operation experiences}

The program and main experiences of the five test runs realized at the SXB pilot plant between May 2019 and June 2020 are summarized in Table 2. Each test run was realized within one calendar week. Preheating of the plant started during the previous week, first by leading hot air through the whole system followed by combusting wood pellets in a separate burner that was connected to the primary gasifier stage. The inner vessels of the filter and the reformer also had electrical heaters, which could be used for preheating as well as for compensating heat losses during normal operation. When the primary stage temperature was raised above $600{ }^{\circ} \mathrm{C}$, pellet feeding was started through the normal feeding system and the gasifier was operated as a combustor. The separate preheating burner was then disclosed. This preheating was continued until the temperature of the secondary zone reached $600{ }^{\circ} \mathrm{C}$. Then, the plant was shifted from combustion to air and steam-blown gasification, and the temperature of the secondary zone was 
Table 2 Summary of the realized test program

\begin{tabular}{|c|c|c|c|c|}
\hline Test run & Plant configuration & $\begin{array}{l}\text { Gasification time and } \\
\text { number of interruptions }\end{array}$ & $\begin{array}{l}\text { Number of set points } \\
\text { (SP) }\end{array}$ & Operational experiences \\
\hline SXB 19/21 & $\begin{array}{l}\text { Gasifier, ceramic } \\
\text { filters, reformer } \\
\text { with Ni-catalysts, } \\
\text { all gas to boiler }\end{array}$ & $\begin{array}{l}60 \mathrm{~h} \\
2 \text { interruptions }\end{array}$ & 4 - all with wood pellets & $\begin{array}{l}\text { Test rig commissioned and } \\
\text { several requirements for } \\
\text { improvements defined. } \\
\text { Principle of steam } / \mathrm{O}_{2} \\
\text { pressurized two-stage gasifica- } \\
\text { tion verified. First results for } \\
\text { gas and tar contents } \\
\text { Main problems: control of the bed } \\
\text { height, pressure drop of the } \\
\text { filter, shortcomings of } \\
\text { automation system }\end{array}$ \\
\hline SXB 19/34 & $\begin{array}{l}\text { Gasifier, metal filters, } \\
\text { reformer with } \\
\text { Ni-catalysts, all gas } \\
\text { to boiler } \\
\text { Continuous dust } \\
\text { feeding before } \\
\text { filter added }\end{array}$ & $\begin{array}{l}70 \mathrm{~h} \\
1 \text { interruption }\end{array}$ & $\begin{array}{l}8 \text { SPs: } \\
\text { - } 4 \text { bark } \\
-2 \text { wood } \\
-2 \text { FRW }\end{array}$ & $\begin{array}{l}\text { Basic operation data with wood, } \\
\text { bark, and forest residue pellets } \\
\text { for the gasifier, filter, and the } \\
\text { reformer. First tests with } \mathrm{CO}_{2} \\
\text { replacing part of steam feed. } \\
\text { Stable filter pressure drop } \\
\text { Problems: bed level control, } \\
\text { blocking of the division plate } \\
\text { between gasifier stages }\end{array}$ \\
\hline SXB 20/07 & $\begin{array}{l}\text { Gasifier, metal filters, } \\
\text { reformer with } \\
\text { Ni/PGM catalysts, } \\
\text { final gas cleaning } \\
\text { unit and FT syn- } \\
\text { thesis in the slip- } \\
\text { stream } \\
\text { Addition of the } \\
\text { venturi-type inlets } \\
\text { to the division plate } \\
\text { separating gasifier } \\
\text { stages }\end{array}$ & $\begin{array}{l}62 \mathrm{~h} \\
\text { Uninterrupted }\end{array}$ & $\begin{array}{l}4 \text { SPs: } \\
-3 \text { bark } \\
-1 \text { wood }\end{array}$ & $\begin{array}{l}\text { Complete gasification, gas } \\
\text { cleaning, and FT synthesis } \\
\text { process operated continuously } \\
\text { without major problems } \\
\text { Operation of FT with biomass } \\
\text { derived syngas alone and with } \\
\text { syngas boosted with } \mathrm{H}_{2} \\
\text { verified } \\
\text { Problems: control of the bed level } \\
\text { was still challenging and bed } \\
\text { height was either increasing or } \\
\text { decreasing in most of the set } \\
\text { points }\end{array}$ \\
\hline SXB 20/11 & $\begin{array}{l}\text { Gasifier, metal filters, } \\
\text { reformer with } \\
\text { Ni/PGM catalysts, } \\
\text { final gas cleaning } \\
\text { unit and FT syn- } \\
\text { thesis in the slip- } \\
\text { stream }\end{array}$ & $\begin{array}{l}70 \mathrm{~h} \\
\text { Uninterrupted }\end{array}$ & $\begin{array}{l}7 \text { SPs: } \\
\text { - } 4 \text { wood } \\
\text { - } 2 \text { bark } \\
\text { - } 1 \text { SFP }\end{array}$ & $\begin{array}{l}\text { Complete gasification, gas } \\
\text { cleaning, and FT synthesis } \\
\text { process operated continuously } \\
\text { without major problems } \\
\text { Operation of FT with biomass } \\
\text { derived syngas alone and with } \\
\text { syngas boosted with } \mathrm{H}_{2} \\
\text { Problems: bed height was either } \\
\text { increasing or decreasing in } \\
\text { most of the set points, pressure } \\
\text { drop in the division plate } \\
\text { increased in wood SPs }\end{array}$ \\
\hline SXB 20/24 & $\begin{array}{l}\text { Gasifier, metal filters, } \\
\text { reformer with } \\
\text { Ni/PGM catalysts, } \\
\text { final gas cleaning } \\
\text { unit and FT syn- } \\
\text { thesis in the slip- } \\
\text { stream } \\
\text { Division plate } \\
\text { between the } \\
\text { gasifier stages } \\
\text { partly removed }\end{array}$ & $\begin{array}{l}85 \mathrm{~h} \\
\text { Uninterrupted }\end{array}$ & $\begin{array}{l}8 \text { SPs: } \\
-6 \text { wood } \\
-2 \text { SFP }\end{array}$ & $\begin{array}{l}\text { Complete gasification, gas } \\
\text { cleaning, and FT synthesis } \\
\text { process operated continuously } \\
\text { without major problems } \\
\text { Testing of the effects of operating } \\
\text { conditions and sulfur content } \\
\text { on the reformer performance } \\
\text { Problems: bed height was either } \\
\text { increasing or decreasing in } \\
\text { most of the set points, pressure } \\
\text { drop in the division plate } \\
\text { increased in wood SPs }\end{array}$ \\
\hline
\end{tabular}


gradually increased to the target level of ca. $800{ }^{\circ} \mathrm{C}$. Simultaneously, the pressure was raised to the target pressure of the test run (0.25-0.4 MPa). Next, the gasifier was operated with a high fuel feed rate and low feed rate of primary gasification air, and a charcoal bed was formed into the primary stage. Finally, the fuel feeding and the feed rates of gasification agents (air, oxygen, steam, $\mathrm{CO}_{2}$, and $\mathrm{N}_{2}$ ) to both stages were set to the target values of the first set point. Then, measurements were carried out during several operating periods (set points) during which the mass flow rates of fuel and gasification agents were kept as constant as possible. After completing the measurements of the final set point, the plant was shut down, inerted by nitrogen, and left to cool down in the nitrogen atmosphere. After about one week of cooling, the plant could be opened for inspection and service.

The first test run, SXB 19/21, which was realized in week 21 of 2019, was focused on commissioning the SXB pilot plant and preliminary testing of the operation of the gasifier, reformer, and filter units. The fuel feeding had to be stopped twice during this test week. At first, too much biomass was fed so that the whole reactor volume of the primary stage was filled with wood. This also blocked the holes in the plate dividing the two gasifier stages. The second stop was caused by an increased filter pressure drop. In both cases, the fuel feeding was stopped and the upper part of the gasifier was operated under slightly oxidative conditions so that carbon deposits were combusted. Then, gasification could be continued rapidly, as the whole plant was still hot and the whole regeneration procedure took less than five hours.

Based on the findings of this test run, several modifications, and improvements to the pilot plant, the control system and the auxiliary systems were realized before the second test run was carried out in week 34 of 2019. A mechanical rotating level detector was added to the upper part of the primary gasification stage because it was difficult to adjust the fuel feeding based on the temperature measurements and gas analysis alone. Robust and reliable radioactive-level sensors that are used e.g. at the industrial Bioneer gasifiers could not be considered at the pilot plant due to their high price and more complicated safety instructions. A continuously operating dust feeder was mounted to help with the creation of a dust cake for protecting the filters from getting blocked by sticky soot particles. The filter vessel was also opened, and the ceramic filter elements used in the first test run were replaced by the robust metal filters.

The second test run, SXB 19/34, was a rather successful test, and measurements were carried out in eight rather stable operating periods (set points) using bark and forest residue pellets as the feedstock. Stable filtration without signs of increasing pressure drop was now reached. This proved that the feeding of additional dust into the raw gas was a successful and required method for avoiding filter blinding. The additive feeding increased the dust content from the initial level of 1-
$2 \mathrm{~g} / \mathrm{m}^{3}$ to $13-25 \mathrm{~g} / \mathrm{m}^{3}$. The feeding of $\mathrm{CO}_{2}$ to the primary and secondary stages of the gasifier was also successfully tested in this test run. The operation had to be interrupted once due to an increased pressure drop between the two gasifier stages. The holes of the division plate had been partly blocked by tars and soot deposits. Fuel feeding was stopped for ca. four hours, and the deposits of the division plate were combusted before continuing the fuel feeding. This time, only the division plate was oxidized and the procedure was stopped before oxidizing the filters and the reformer, as there was no sign of deposit formation.

In the first two test runs, the reformer was loaded with commercial nickel-based catalysts. Stable operation without signs of pressure drop increase due to soot formation was reached at all set points. The catalysts were removed from the reformer after test run SXB 19/34, and it could be noted that there were no carbon deposits or signs of catalyst breaking. After this test run, the catalyst loading was changed and two precious metal development catalysts of Johnson Matthew were installed into the reformer as described in [26].

Before the third test run, SXB 20/07, the division plate of the SXB gasifier was equipped with venturi-type inlet tubes, through which the raw gas was led from the primary updraft stage to the second stage. These inlets were also equipped with central air-feeding nozzles. This seemed to help in preventing deposit formation and consequently the test run SXB 20/07 could be carried out as an uninterrupted continuous operation. This test run was the first test, where a slipstream of the syngas was taken to the final gas cleaning and compression unit and finally led into the Fischer-Tropsch synthesis. The test run was successful and consisted of a total of 62 gasification hours, including $39 \mathrm{~h}$ of continuous operation of the FT unit with syngas. Bark pellets and wood chips were used as feedstocks. After this test run, only the gasifier was opened for service, while the filter unit and the reformer were not opened. The front surfaces of the reformer beds checked by the endoscope looked clean.

Test run SXB 20/11 was the second validation test for the complete gasification, gas cleaning, and FT-synthesis process, and it could be carried out as an uninterrupted test with $70 \mathrm{~h}$ of gasification and $61 \mathrm{~h}$ of continuous FT operation with syngas. Process operation was verified with wood, bark, and sunflower husk pellets. The FT unit was operated both with biomassderived syngas alone and by mixing additional hydrogen into the syngas. In the latter operation mode, the $\mathrm{CO}_{2}$ recycling was simulated by feeding $\mathrm{CO}_{2}$ into the primary stage of the gasifier, where it replaced most of the gasification steam. The test run was very successful and the complete process could be operated according to the test plan, which included seven steady-state operation periods for carrying out all required measurements. However, one mechanical problem was met. The grate system and the bottom ash removal could not be operated due to a mechanical failure in the pressure sealing 
systems. This did not have significant effects on the results, as the primary stage has enough space for the ash produced during 3-4 days of operation. The used pelletized feedstocks also formed a stable bed, even without agitation by the rotating grate.

After test run SXB 20/11, the gasification reactor and the reformer vessel were opened for service and modifications. The reformer was again clean and there were no signs of carbon deposits. The filter was not opened as the pressure drop had been constant. The plate, which divided the lower updraft fixed-bed and the secondary zone of the gasifier, was modified by replacing the four small holes with one central opening of $0.4 \times 0.4 \mathrm{~m}^{2}$. One of the main aims of the last test run was to examine the role of the division plate in tar decomposition and gasifier stability. The reformer catalysts used in the test runs 20/07 and 20/11 were also removed and after taking samples for post mortem analysis, part of the catalysts were reloaded together with a platinum-based methane catalyst that was installed into the second bed.

The last test run, SXB 20/24, was realized again as a continuous operation with $85 \mathrm{~h}$ of gasification. This test run had to be carried out without grate rotation and ash removal as it was not possible to repair the broken seal of the grate rotation system. That is why the major part of the test run was carried out with the low-ash wood pellets, and the ash-containing sunflower husk pellets were used at the later stage of the test run. In this test run, the fuel feed rate was controlled carefully based on the measured gasifier temperatures and the methane content of the raw gas. The bed level was kept clearly below the rotating level controller located at the top of the primary zone at all times. This resulted in better material balances than in previous test runs, because the inventory of the charcoal bed was more or less constant during the measured test periods.

Key temperatures of the gasifier during test run SXB 20/24 are illustrated in Fig. 4. At the beginning of the test run, the primary zone is cooling down after the plant preheating, which was realized by operating the primary zone as a biomass combustor. Simultaneously, the refractories of the secondary zone are still heating up. These tendencies can still be seen in the temperature trends of the first set point A. Then in the last set points after the operation with sunflower husks (E), the bed level is higher due to the build-up of the ash layer at the bottom of the gasifier. This can be seen as decreasing primary zone temperatures, although the fuel feed rate is in balance with charcoal consumption.

During the five weeks of operation there were signs of corrosion or erosion in the internal structures of the gasifier, filter elements, or the internal vessels and catalysts of the reformer. The catalyst basket structure of the 2 nd gasification stage looked intact and there was only a light dust layer on the top surfaces of the catalysts. No deposits were found after any test run from the walls of the secondary gasifier stage or from the gas cooler or pipe leading to the filter unit. After some test runs, there were, however, some ash sinters in the bottom ash bed. This was evidently due to poor operation of the grate system.

\section{Results and discussion}

\subsection{Gasifier performance}

Over the five test weeks, measurements were carried out in 3 20-h-long periods (set points), during which the mass flow rates of input streams were kept as constant as possible. The biomass feed rate was determined by weighing all feedstock batches when they were loaded into the upper lock-hopper silo. Based on these weighing results, the metering feeding screw was calibrated to form a feedstock-specific correlation between the mass flow rate and the rotation speed. All input mass flow rates of feed gases and steam were measured with calibrated flow meters. All the dust captured by the filter unit was collected for further analysis. The gas composition and tar contents were measured at all set points both before and after the reformer. Elemental mass balances over the gasifier and reformer were calculated for the set point periods based on average measuring results using similar principles as described in [12]. The raw gas flow rate could not be measured with the same accuracy as the input mass flows. The carbon balance could not be used for the calculation of dry gas flow rate because the charcoal inventory in the primary gasifier stage was not always completely stable. Consequently, in the used mass balance calculation method, nitrogen balance was used to calculate the dry gas flow rates and hydrogen balance to calculate the water vapor flow rate of raw gas and reformed gas. When the closures of carbon and oxygen balances are satisfactory and the measured water vapor contents and those calculated from the hydrogen balance are close to each other, it can be concluded that the results are accurate and the operation has been close to steady-state conditions. The volumetric concentrations are presented at standard conditions $\left(273.15 \mathrm{~K}{ }^{\circ} \mathrm{C}\right.$ and $101.325 \mathrm{kPa}$ ), and the molar flows are converted to volume flows using the molar volume of an ideal gas of $22.41 \mathrm{dm}^{3} / \mathrm{mol}$. It should be noted that bottom ash could not be removed in a representative way, as this would have required several days or even weeks of operation at the same operating conditions. However, based on previous updraft gasification experiences, see [21,23], it can be concluded that bottom ash would be fully oxidized when it is flowing through the combustion zone of the gasifier.

In the first three test runs, the fuel feed rate was not always in a good balance with the charcoal consumption in the primary gasifier stage, and the carbon inventory of the bed was often either slowly increasing or decreasing. In the set points of two last test runs, the feed rate was in better balance with consumption. The main operating conditions and calculated 


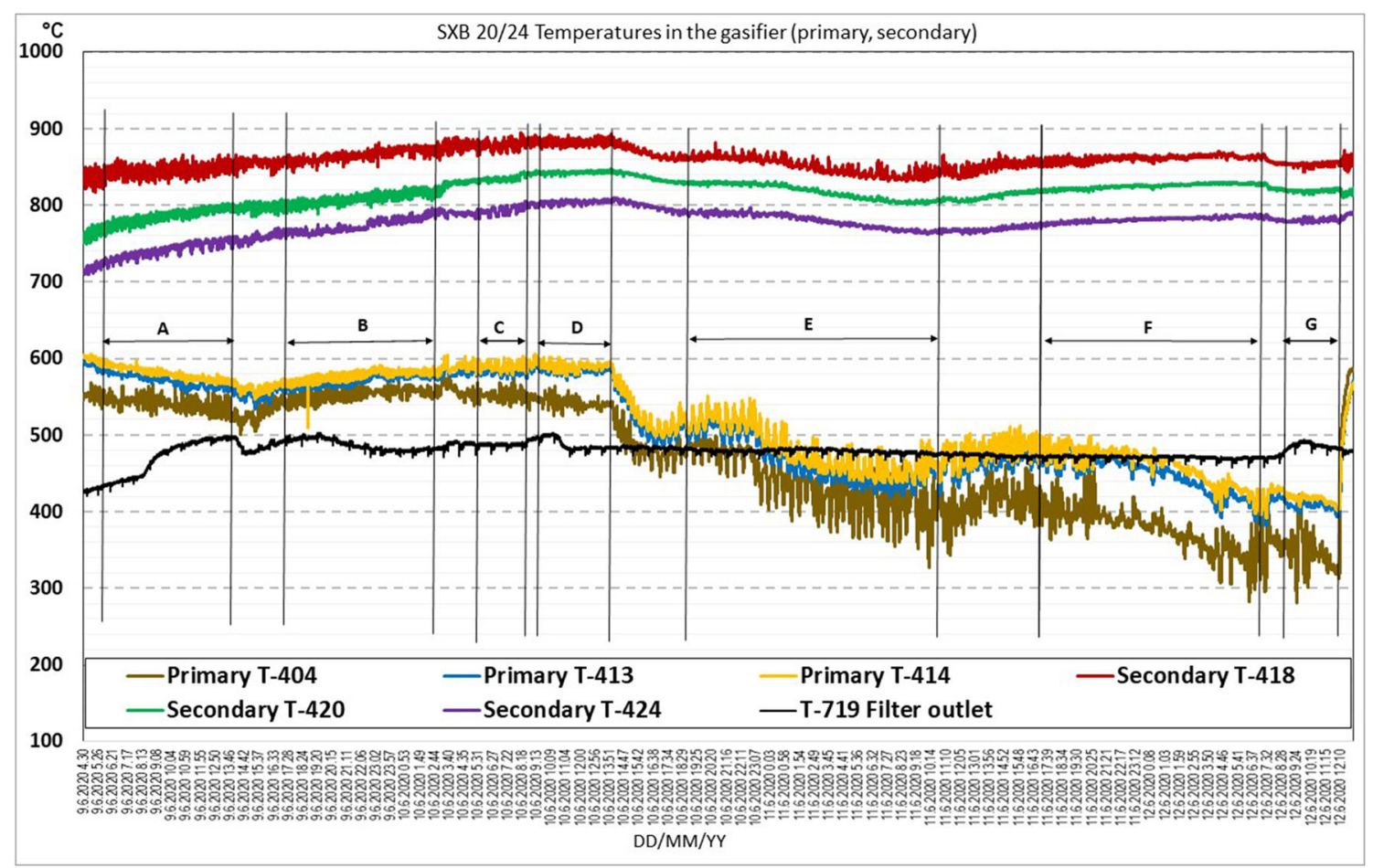

Fig. 4 Temperatures of the filter and the primary and secondary zones of the gasifier

performances of selected steady-state set points realized with different feedstocks are summarized in Table 3. This table includes only the set points during which the bed inventory has been close to balance, which can be judged based on the determined carbon balance.

In process modeling of gasifiers, it is often assumed that the main gas components $\mathrm{CO}, \mathrm{H}_{2} \mathrm{O}, \mathrm{H}_{2}$, and $\mathrm{CO}_{2}$ approach the equilibrium of water gas shift reaction $\left(\mathrm{CO}+\mathrm{H}_{2} \mathrm{O} \leftrightarrow \mathrm{H}_{2}+\right.$ $\mathrm{CO}_{2}$ ), and this has often been a relatively valid assumption in fluidized-bed gasification, at least when the gasifier is operated at above $850{ }^{\circ} \mathrm{C}$ [35]. In Fig. 5, the equilibrium coefficients calculated from the actual gas analyses (from Table 3 and Table 5) determined before and after the reformer are compared with the values calculated with the formula given in [36]. In this figure, the measured values are plotted against the average temperature of the secondary zone of the gasifier and the outlet temperature of the reformer. These results show that in the SXB gasifier, the raw gas does not approach the equilibrium of water gas shift reaction, and the $\mathrm{CO}$ and $\mathrm{H}_{2} \mathrm{O}$ concentrations are higher than those at equilibrium. This could be expected, as the secondary zone of the SXB gasifier has a rather open structure and there are no bed material particles present in the gas, which would catalyze the shift reaction as in fluidized-bed gasifiers. The equilibrium approach seems to be more valid for the final gas after the catalytic reformer, which is practical when considering overall process modeling and essential for realizing the principal idea of the FlexCHX process.
In biomass gasification, hydrocarbon gases and tars are formed from the volatile matter of biomass, and the decomposition and removal of these components are among the key challenges of biomass gasification systems. In the gasification process of this paper, tar control is carried out in three separate processing units, firstly in the secondary gasifier stage, secondly in the catalytic reformer, and finally in the active cokebased sorbent bed. The raw gas of the SXB gasifier contained 5-8 vol- $\%$ methane, 1-2 vol- $\% \mathrm{C}_{2}$-hydrocarbons, and the benzene and tar concentrations were in the range 10-14 g/ $\mathrm{m}^{3}$ and $5-12 \mathrm{~g} / \mathrm{m}^{3}$ respectively. Thus, most of the updraft tars were decomposed in the secondary stage of the gasifier, and the measured concentrations of tars and hydrocarbon gases were of the same order of magnitude as determined previously for the steam-oxygen blown fluidized-bed gasification [29] or dual fluidized-bed steam gasification [37, 38]. Typical tar compositions for the raw gas and the reformed gas are presented in Table 4, which shows the tar analysis data for clean wood and sunflower husks. It can be noted that the main components of the tars determined from the raw gas obtained with both feedstocks are benzene and naphthalene, but the gas also contains high concentrations of higher-molecular-weight polycyclic components as well as toluene and indene. The tar composition of the raw gas is rather similar for both feedstocks. In the case of sunflower husks, the contents of nitrogen-containing heterocyclic compounds are, however, higher due to the high nitrogen content of this feedstock. The difference in the reformer efficiency can be seen in the 
Table 3 Main operating conditions of the gasifier at selected set points

\begin{tabular}{|c|c|c|c|c|c|c|c|c|c|c|}
\hline Set point & 19/34G & $19 / 34 \mathrm{H}$ & 20/07D & $20 / 11 \mathrm{~A} 2$ & 20/11B & $20 / 24 \mathrm{D}$ & 20/24F1 & 20/11D & $20 / 11 \mathrm{E}$ & 20/24E2 \\
\hline Duration, hours & 4.0 & 3.0 & 4.0 & 8.0 & 6.5 & 5.0 & 6.0 & 2.2 & 11.0 & 11.0 \\
\hline Feedstock & $\mathrm{FRW}+\mathrm{K}$ & $\mathrm{FRW}+\mathrm{K}$ & $\mathrm{WCH}$ & WP & WP & WP & WP & $\mathrm{BP}$ & SFP & SFP \\
\hline Moisture content, \% & 7.5 & 7.5 & 9.5 & 7.4 & 7.4 & 7.6 & 7.6 & 9.2 & 7.7 & 7.7 \\
\hline Feed rate, $\mathrm{g} / \mathrm{s}$ & 10.0 & 10.0 & 14.2 & 11.7 & 11.7 & 11.9 & 11.9 & 10.6 & 10.5 & 13.6 \\
\hline \multicolumn{11}{|l|}{ Gasifier feed gases, $\mathrm{g} / \mathrm{s}$} \\
\hline Air to stage $1 \mathrm{a}$ & 4.0 & 3.0 & 3.0 & 2.4 & 2.4 & 0 & 0 & 3 & 2.4 & 0 \\
\hline $\mathrm{O}_{2}$ to stage 1 & 1.79 & 1.96 & 2.40 & 2.59 & 2.59 & 2.70 & 2.30 & 2.59 & 2.49 & 2.30 \\
\hline Steam to stage 1 & 9.0 & 4.0 & 7.6 & 8.9 & 4.5 & 9.5 & 7.8 & 8.1 & 9.1 & 9 \\
\hline $\mathrm{CO}_{2}$ to stage 1 & 0 & 4.5 & 1.9 & 1.99 & 6.48 & 3.00 & 2.5 & 2.49 & 2.05 & 2.5 \\
\hline $\mathrm{O}_{2}$ to stage 2 & 1.37 & 1.04 & 1.7 & 1.38 & 1.19 & 1.90 & 2.00 & 1.00 & 1.16 & 2.00 \\
\hline $\mathrm{N}_{2}$ to stage 2 & 3.41 & 2.60 & 3.30 & 2.42 & 0.43 & 4.40 & 4.20 & 1.01 & 1.35 & 4.20 \\
\hline $\mathrm{CO}_{2}$ to stage 2 & 0 & 0 & 0 & 0.00 & 1.51 & 0.00 & 0.00 & 0.62 & 0.32 & 0.00 \\
\hline Pressure at gasifier top, $\mathrm{MPa}$ & 0.25 & 0.25 & 0.25 & 0.25 & 0.25 & 0.20 & 0.20 & 0.25 & 0.25 & 0.20 \\
\hline \multicolumn{11}{|l|}{ Gasifier temperatures, ${ }^{\circ} \mathrm{C}$} \\
\hline Top of stage 1 & 511 & 482 & 580 & 523 & 535 & 588 & 453 & 552 & 526 & 461 \\
\hline Average, stage 2 & 855 & 852 & 862 & 847 & 848 & 857 & 834 & 850 & 852 & 819 \\
\hline At gasifier outlet & 800 & 793 & 798 & 780 & 780 & 804 & 781 & 785 & 792 & 776 \\
\hline \multicolumn{11}{|l|}{ Filter operation } \\
\hline Temperature in inlet, ${ }^{\circ} \mathrm{C}$ & 596 & 584 & 503 & 571 & 587 & 523 & 489 & 599 & 500 & 505 \\
\hline Temperature in outlet, ${ }^{\circ} \mathrm{C}$ & 527 & 519 & 490 & 494 & 497 & 500 & 471 & 503 & 464 & 479 \\
\hline Pressure drop, mbar & 126 & 123 & 89 & 55 & 49 & 49 & 252 & 63 & 126 & 252 \\
\hline Dust feeding, $\mathrm{g} / \mathrm{s}$ & 0.7 & 0.7 & 0.4 & 0.6 & 0.7 & 0.7 & 0.7 & 0.7 & 0.7 & 0.7 \\
\hline Dust content in inletb, $\mathrm{g} / \mathrm{m}^{3}$ STP & 14.5 & 14.5 & 14.5 & 14.5 & 14.5 & 13.4 & 12.2 & 14.5 & 14.5 & 12.8 \\
\hline Face velocity, $\mathrm{cm} / \mathrm{s}$ & 1.6 & 1.3 & 1.7 & 1.6 & 1.5 & 2.1 & 1.8 & 1.5 & 1.4 & 2.1 \\
\hline \multicolumn{11}{|l|}{ Gas after filter by volume, dry basis } \\
\hline $\mathrm{CO}(\%)$ & 13.3 & 16.1 & 14.6 & 19.5 & 23.2 & 19.3 & 19.3 & 16.7 & 15.4 & 17.0 \\
\hline $\mathrm{CO}_{2}(\%)$ & 27.2 & 37.5 & 31.6 & 30.3 & 41.5 & 31.0 & 32.4 & 36.0 & 36.1 & 33.1 \\
\hline $\mathrm{H}_{2}(\%)$ & 15.9 & 11.1 & 20.2 & 19.7 & 14.8 & 17.7 & 17.4 & 18.0 & 19.5 & 19.9 \\
\hline $\mathrm{N}_{2}(\%)$ & 35.9 & 27.9 & 26.9 & 22.6 & 13.5 & 24.0 & 22.5 & 21.8 & 20.3 & 21.2 \\
\hline $\mathrm{CH}_{4}(\%)$ & 6.6 & 6.5 & 6.0 & 6.6 & 5.9 & 6.5 & 6.9 & 6.3 & 7.3 & 6.7 \\
\hline $\mathrm{C}_{2} \mathrm{H}_{2}(\%)$ & 0.04 & 0.04 & 0.02 & 0.03 & 0.03 & 0.07 & 0.05 & 0.03 & 0.04 & 0.05 \\
\hline $\mathrm{C}_{2} \mathrm{H}_{4}(\%)$ & 0.9 & 0.9 & 0.6 & 1.0 & 0.8 & 1.3 & 1.3 & 1.0 & 1.2 & 1.6 \\
\hline $\mathrm{C}_{2} \mathrm{H}_{6}(\%)$ & 0.1 & 0.1 & 0.1 & 0.2 & 0.2 & 0.2 & 0.2 & 0.2 & 0.2 & 0.4 \\
\hline $\mathrm{C}_{3}-\mathrm{C}_{5} \mathrm{H}_{\mathrm{y}}(\%)$ & 0.01 & 0.01 & 0.00 & 0.00 & 0.00 & 0.00 & 0.01 & 0.00 & 0.00 & 0.02 \\
\hline Benzene, $\mathrm{g} / \mathrm{m}^{3}$ in dry gas & 10.7 & 12.7 & 6.0 & 11.2 & 10.3 & 12.9 & 13.1 & 13.1 & 14.1 & 13.2 \\
\hline $\operatorname{Tars}^{\mathrm{c}}, \mathrm{g} / \mathrm{m}^{3}$ & 5.9 & 9.2 & 1.7 & 6.1 & 5.7 & 10.8 & 12.1 & 8.2 & 8.1 & 12.2 \\
\hline Heavier than naphthalene ${ }^{\mathrm{d}}, \mathrm{g} / \mathrm{m}^{3}$ & 2.4 & 4.1 & 0.54 & 2.4 & 2.2 & 4.6 & 4.7 & 3.5 & 3.2 & 4.0 \\
\hline $\mathrm{NH}_{3}, \mathrm{mg} / \mathrm{m}^{3}$ in dry gas & nd & nd & 862 & 400 & 363 & nd & nd & 1887 & 3578 & 2627 \\
\hline Wet gas flow, $\mathrm{m}^{3} / \mathrm{h}$ & 104 & 85 & 121 & 111 & 98 & 116 & 106 & 101 & 104 & 118 \\
\hline \multicolumn{11}{|l|}{ Wet gas $\mathrm{H}_{2} \mathrm{O}$ content, by volume } \\
\hline From tar samples (\%) & 48.6 & 36.5 & 38.4 & 41.0 & 31.5 & 43.0 & 39.8 & 42.5 & 44.9 & 39.4 \\
\hline From H-balance (\%) & 43.8 & 30.3 & 39.9 & 42.9 & 31.6 & 43.5 & 40.3 & 43.4 & 42.3 & 39.1 \\
\hline \multicolumn{11}{|l|}{ Calculated performances } \\
\hline Carbon loss in filter ash, $\%$ & 1.6 & 1.8 & 0.5 & 1.1 & 0.5 & 0.7 & 0.6 & 0.7 & 1.2 & 0.7 \\
\hline C-balance closure (out/in) & 0.93 & 0.93 & 0.84 & 1.03 & 0.98 & 1.03 & 0.98 & 0.96 & 1.02 & 0.93 \\
\hline O-balance closure (out/in) & 1.01 & 1.02 & 1.00 & 1.00 & 1.00 & 1.01 & 0.97 & 1.00 & 1.00 & 0.99 \\
\hline $\mathrm{O}_{2}$ feed, $\%$ of stoich.combust. & 31.9 & 28.8 & 27.3 & 29.9 & 28.7 & 29.8 & 27.9 & 30.6 & 30.0 & 23.7 \\
\hline Steam to fuel ratio, $\mathrm{kg} / \mathrm{kg}_{\mathrm{daf}}$ & 1.03 & 0.46 & 0.59 & 0.83 & 0.42 & 0.87 & 0.71 & 0.88 & 0.97 & 0.74 \\
\hline $\mathrm{CO}_{2}$ feed to fuel ratio, $\mathrm{kg} / \mathrm{kg}_{\text {daf }}$ & 0 & 0.51 & 0.15 & 0.18 & 0.74 & 0.27 & 0.23 & 0.34 & 0.25 & 0.21 \\
\hline
\end{tabular}


Table 3 (continued)

\begin{tabular}{|c|c|c|c|c|c|c|c|c|c|c|}
\hline Set point & 19/34G & 19/34H & 20/07D & $20 / 11 \mathrm{~A} 2$ & 20/11B & 20/24D & 20/24F1 & 20/11D & $20 / 11 \mathrm{E}$ & 20/24E2 \\
\hline K-shift. From wet gas analysis & 0.41 & 0.59 & 0.65 & 0.41 & 0.57 & 0.37 & 0.43 & 0.50 & 0.62 & 0.60 \\
\hline K-shift. Calculated at stage 2 temperature & 0.79 & 0.80 & 0.78 & 0.83 & 0.82 & 0.80 & 0.86 & 0.83 & 0.81 & 0.90 \\
\hline
\end{tabular}

${ }^{a}$ Including air feed to the venturi inlet of the division plate

${ }^{b}$ Determined based on total mass of removed filter dust during the set point period

${ }^{\mathrm{c}}$ Sum of the concentrations of tar components heavier than benzene in dry gas

${ }^{\mathrm{d}}$ Sum of the concentrations of tar components heavier than naphthalene in dry gas

${ }^{\mathrm{e}}$ Defined by the carbon content and mass flow of dust separated by the filter and the carbon input in feedstock and filter additive

measured tar contents of reformer gas. With the low-sulfur wood pellets, almost complete conversion is achieved for all other compounds than benzene, and even the benzene content is low. In sunflower husk gasification, the benzene content is more than ten times higher, and additionally, the tar contains a significant amount of residual naphthalene. However, the concentrations of higher-molecular-weight tars in the reformed syngas are also negligible with sunflower husks.

Figure 6 shows the yields of methane and hydrocarbon gases calculated as a percentage of the volatile matter of gasified biomass feed. Figure 7 shows similarly the yields of benzene and tars. This data includes all set points from 2020 test runs. The results are shown separately for the initial gasifier design, where the two gasifier stages were separated by the division plate and for the more open design applied in the last test run, SXB 20/24. The division plate had a significant effect on tar decomposition, while similar effects cannot be found from the results of light hydrocarbon gases and benzene. The results indicate that the temperature of the secondary zone should be higher than $860^{\circ} \mathrm{C}$ to further improve tar decomposition significantly. However, this is not considered beneficial for the overall process efficiency, as the gas is cooled to $600{ }^{\circ} \mathrm{C}$ before filtration and then preheated again in the reformer. The main objective of the secondary zone is to reduce the tar contents of an updraft gasifier to levels, which will allow stable filtration and avoid carbon deposit formation in the catalytic reformer.

In biomass gasification, feedstock nitrogen is converted to ammonia, nitrogen-containing tars, $\mathrm{HCN}$, and molecular nitrogen $[39,40]$. In fluidized-bed gasifiers, ammonia is the dominating fuel nitrogen compound $[12,38]$. In these SXB gasification tests, ammonia concentrations were measured at some set points and the tar samples were also analyzed for species containing nitrogen. Figure 8 illustrates the measured ammonia concentrations for the filtered raw gas and the reformed gas as well as the calculated conversions of feedstock nitrogen to ammonia determined based on the raw gas results. The fuel nitrogen conversions to ammonia determined for wood and bark pellets were lower than determined previously in fluidized-bed gasification tests with similar feedstocks [12]. Unfortunately, HCN was not sampled from the raw gas of the SXB gasifier. However, the HCN concentrations measured
Fig. 5 Comparison of the measured and calculated equilibrium coefficients of shift reaction

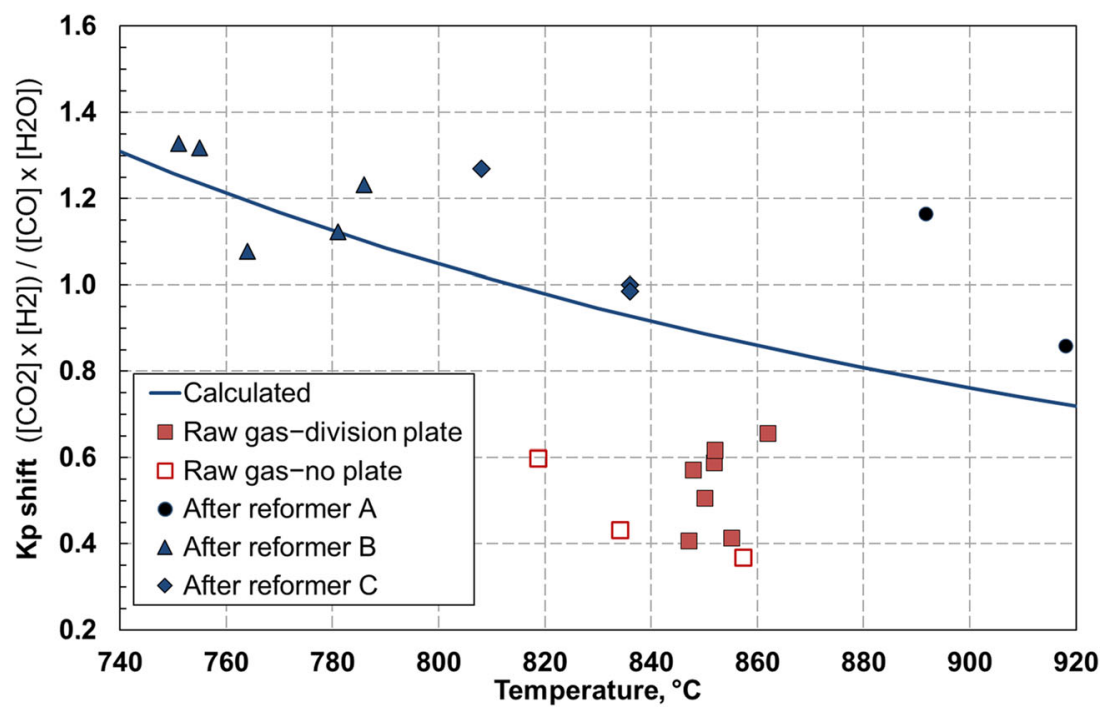


Table 4 Examples of tar analyses for the raw gas after filtration and reformed syngas

\begin{tabular}{|c|c|c|c|c|}
\hline Concentration, $\mathrm{mg} / \mathrm{m}^{3}{ }_{\text {stp }}$ (in dry gas) & $\begin{array}{l}\text { SXB 20/24D } \\
\text { After filter }\end{array}$ & $\begin{array}{l}\text { SXB 20/24D } \\
\text { After reformer }\end{array}$ & $\begin{array}{l}\text { SXB 20/24E2 } \\
\text { After filter }\end{array}$ & $\begin{array}{l}\text { SXB 20/24E2 } \\
\text { After reformer }\end{array}$ \\
\hline Benzene & 12,916 & 215 & 13,172 & 3942 \\
\hline Pyridine & 55 & 0 & 503 & 0 \\
\hline 1H-Pyrrole & 0 & 0 & 10 & 0 \\
\hline Toluene & 739 & 0 & 1774 & 0 \\
\hline Ethylbenzene & 0 & 0 & 13 & 0 \\
\hline m-Xylene & 0 & 0 & 73 & 0 \\
\hline Ethynylbenzene & 0 & 0 & 10 & 0 \\
\hline Styrene & 271 & 0 & 361 & 0 \\
\hline o-Xylene & 0 & 0 & 0 & 0 \\
\hline Benzaldehyde & 0 & 0 & 0 & 0 \\
\hline Phenol & 59 & 0 & 364 & 0 \\
\hline Benzonitrile & 0 & 0 & 92 & 0 \\
\hline 4-Methylstyrene & 44 & 0 & 119 & 0 \\
\hline Indene & 706 & 0 & 1107 & 0 \\
\hline o-Cresol & 0 & 0 & 0 & 0 \\
\hline $\mathrm{m}+\mathrm{p}$-Cresol & 0 & 0 & 15 & 0 \\
\hline Naphthalene & 4248 & 3 & 3759 & 249 \\
\hline Quinoline & 0 & 0 & 95 & 0 \\
\hline Quinazoline & 0 & 0 & 0 & 0 \\
\hline Isoquinoline & 0 & 0 & 33 & 0 \\
\hline 1H-Indole & 0 & 0 & 174 & 0 \\
\hline 2-Methylnaphthalene & 84 & 0 & 175 & 0 \\
\hline 1-Methylnaphthalene & 51 & 0 & 88 & 0 \\
\hline Biphenyl & 92 & 0 & 100 & 0 \\
\hline 2-Ethylnaphthalene & 0 & 0 & 0 & 0 \\
\hline 1.6 Dimethylnaphthalene & 53 & 0 & 55 & 0 \\
\hline Acenaphthylene & 922 & 0 & 765 & 0 \\
\hline Acenaphthene & 33 & 0 & 30 & 0 \\
\hline Dibenzofuran & 198 & 0 & 104 & 0 \\
\hline Bibenzyl & 0 & 0 & 0 & 0 \\
\hline 2-Methyl-1-Naphthol & 0 & 0 & 0 & 0 \\
\hline Fluorene & 386 & 0 & 405 & 0 \\
\hline Phenanthrene & 894 & 0 & 627 & 0 \\
\hline Anthracene & 275 & 0 & 250 & 0 \\
\hline Carbazole & 0 & 0 & 0 & 0 \\
\hline 1-Phenylnaphthalene & 0 & 0 & 0 & 0 \\
\hline 2-Methylanthracene & 0 & 0 & 41 & 0 \\
\hline 4H-Cyclopenta(def)Phenanthrene & 114 & 0 & 104 & 0 \\
\hline Fluoranthene & 471 & 0 & 302 & 0 \\
\hline Pyrene & 441 & 0 & 294 & 4 \\
\hline 2,3-Benzofluorene & 0 & 0 & 40 & 0 \\
\hline 1,1 Binaphthyl & 0 & 0 & 0 & 0 \\
\hline 1,2 Benzanthracene & 88 & 0 & 67 & 0 \\
\hline Chrysene & 101 & 0 & 74 & 0 \\
\hline 2,3 Benzanthracene & 0 & 0 & 0 & 0 \\
\hline Benzo(b)fluoranthene & 68 & 0 & 34 & 0 \\
\hline Benzo(e)pyrene & 61 & 0 & 23 & 0 \\
\hline Benzo(a)pyrene & 149 & 0 & 101 & 0 \\
\hline
\end{tabular}


Table 4 (continued)

\begin{tabular}{lllll}
\hline Concentration, $\mathrm{mg} / \mathrm{m}^{3}$ stp (in dry gas) & $\begin{array}{l}\text { SXB 20/24D } \\
\text { After filter }\end{array}$ & $\begin{array}{l}\text { SXB 20/24D } \\
\text { After reformer }\end{array}$ & $\begin{array}{l}\text { SXB 20/24E2 } \\
\text { After filter }\end{array}$ & $\begin{array}{l}\text { SXB 20/24E2 } \\
\text { After reformer }\end{array}$ \\
\hline Perylene & 0 & 0 & 0 & 0 \\
Indeno(1,2,3-cd) pyrene & 56 & 0 & 21 & 0 \\
Benzo(ghi)perylene & 54 & 0 & 0 & 0 \\
Anthanthrene & 41 & 0 & 0 & 0 \\
Coronene & 0 & 0 & 0 & 0 \\
Identified tars & 10,753 & 2.9 & 12,204 & 254 \\
Identified tars + benzene & 23,668 & 217 & 25,376 & 4195 \\
Total tars + benzene (incl. unknown) & 24,204 & 217 & 26,131 & 4195 \\
Identified, \% & 97.8 & 100.0 & 97.1 & 100.0 \\
\hline
\end{tabular}

after the reformer were very low, varying in the range of $0.5-2$ vol-ppm (parts per million by volume). Tar-nitrogen represented $2.9-3.0 \%$ of feedstock nitrogen in the tests with sunflower husks, while the concentrations of the nitrogencontaining tar species in wood gasification were below the detection limit of tar analysis (corresponding to $<0.1 \mathrm{mg} / \mathrm{m}^{3}$ ).

\subsection{Filtration experiences}

In this gasification process, hot filtration has an important role in protecting the fixed-bed reformer from dust deposits. In the test runs of this paper, the filter was operated at a temperature of 500 $600^{\circ} \mathrm{C}$. According to the previous fluidized-bed gasification tests described in $[12,33]$ as well as the thermodynamic projections [41], this temperature range is also suitable for removing a major part of alkali metals together with particulate removal. This is also beneficial as alkali metals could also be potential poisons for the reformer catalysts or they could condense on the cold surfaces of the gas cooler after reforming.
Test run SXB 19/34 and all the three test weeks carried out in 2020 were realized with the same set of novel metal filters, and the filter unit was opened only after the last test run. The operating temperatures and the accumulated operating hours of filters under gasification conditions are illustrated in Fig. 9. Additionally, the filter elements were exposed to oxidative conditions during plant pre-heating and shut-down procedures. These types of rigid barrier filters act as total filters, and the dust contents measured after filtration are found to be below the detection limit of the sampling and measuring system as reported for previous fluidized-bed tests [30, 33]. Thus, isokinetic particulate sampling with the heated probe was realized only in one of the SXB test runs, resulting in a completely clean sample. The penetration of dust through the filters would also result in a rapid increase of reformer pressure drop, and dust particles would have been visible at the top of the reformer beds as well as in the sampling systems for gases and tars. All SXB tests could, however, be carried out without any signs of dust penetration through the filter.
Fig. 6 Yields of methane and $\mathrm{C}_{2}$ hydrocarbon gases in the SXB gasifier

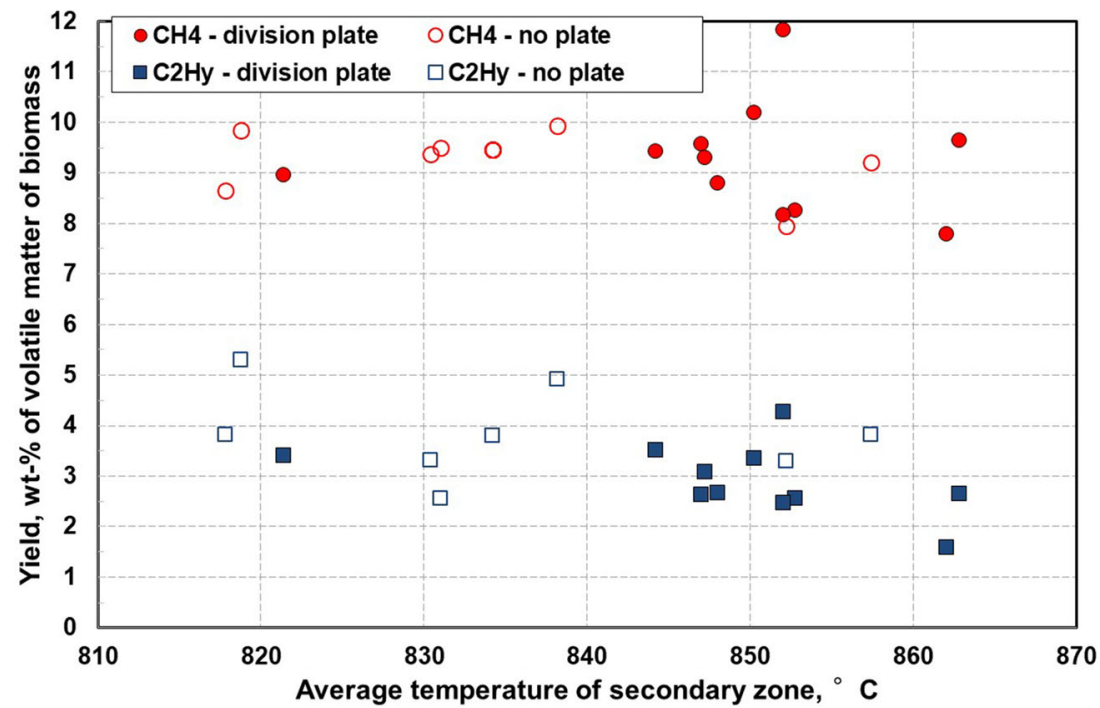


Fig. 7 Yields of benzene and tars in the SXB gasifier

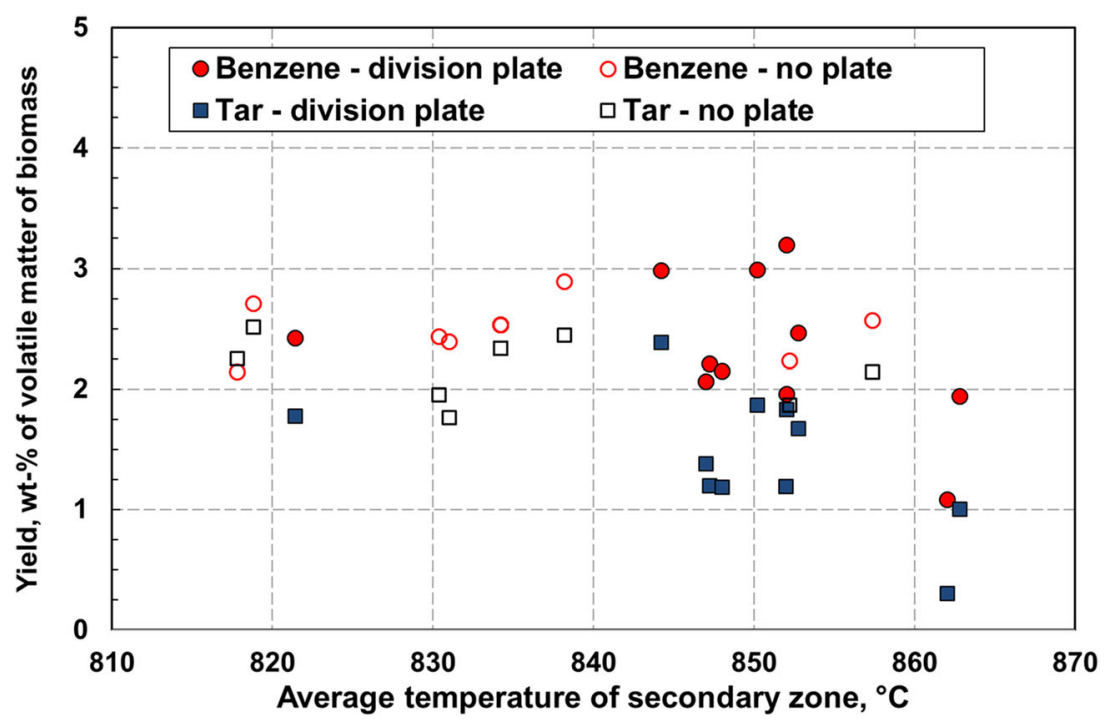

In the SXB gasifier, most of the biomass ash retains in the bottom bed of the primary updraft stage of the gasifier. As the gas velocity at the top of the primary stage is also very low, estimated to be of the order of $5 \mathrm{~cm} / \mathrm{s}$, only a very small amount of char particles elutriate out of the gasifier. This results in too low a particulate concentration to form a proper dust cake on the filter elements. Thus, tars and sticky soot aerosols will directly meet the filter element structure, which leads to the formation of sticky deposits that cannot be cleaned by pulse cleaning. Consequently, additional particulates must be fed into the raw gas entering into the filter unit. In the SXB tests, a mixture of fine sand and either dolomite or magnesium oxide (particle size $<100 \mu \mathrm{m}$ ) was used as the additive. The additive was fed to the raw gas at the top of the raw gas cooler. The dust contents of raw gas in the different set points shown in Table 3 were calculated based on the weighed mass of ash collected by the filter and the determined gas flow rate.
The pressure drop trends of the filter and the catalytic reformer during the three test runs carried out in 2020 are illustrated in Fig. 10. The face velocity (gas flow rate divided by the filtration surface) also shown in Table 3 was calculated based on the actual volume flow of the raw gas at the temperature and pressure of the filter inlet and the total surface of the 12 filter elements. The face velocity was mostly in the range of $1.5-2.2 \mathrm{~cm} / \mathrm{s}$, which was considered to be close to the upper limit of stable operation. The pressure drop of the reformer did not show any increasing tendencies during any of the test periods, indicating that there were no dust leakages through the filter unit and that severe soot formation did not take place in the reformer. The filter pressure drop was more sensitive to the operating conditions and gasifier performance. In test run SXB 20/07, the bed level was raised at the beginning of the test run rather rapidly, which could be seen as a steeply increasing pressure drop. This trend also continued at the
Fig. 8 Measured ammonia concentrations (in dry gas) and calculated conversions of feedstock nitrogen to ammonia

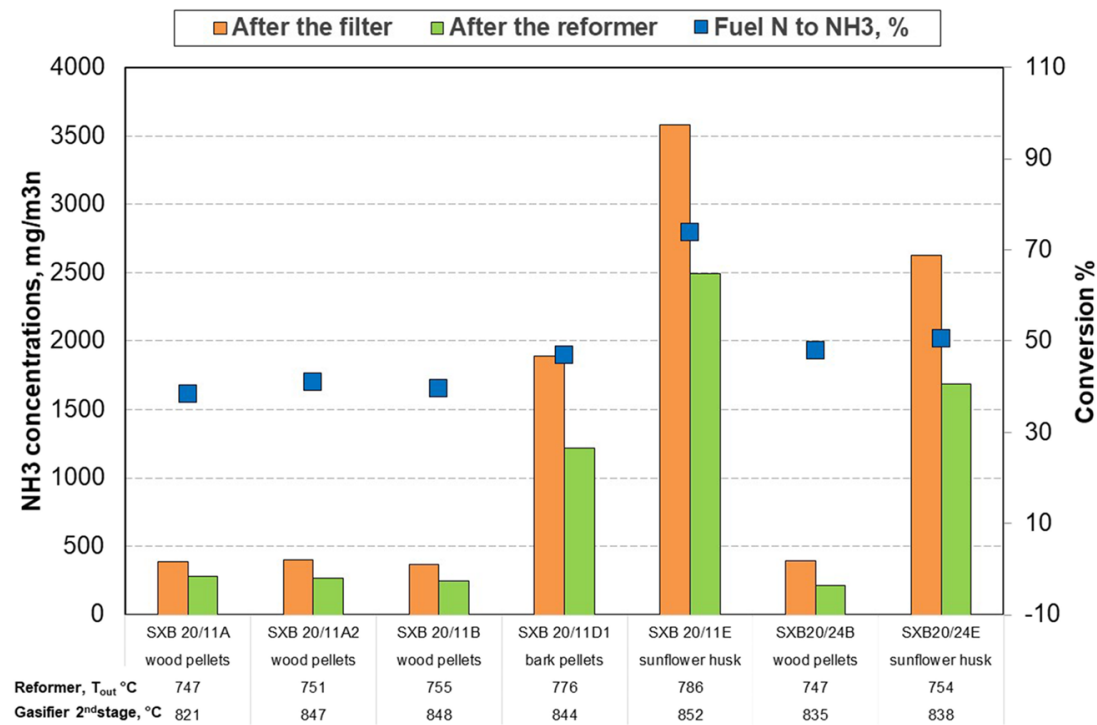


Fig. 9 Operating temperatures and cumulative operation time of the filters in the SXB test runs

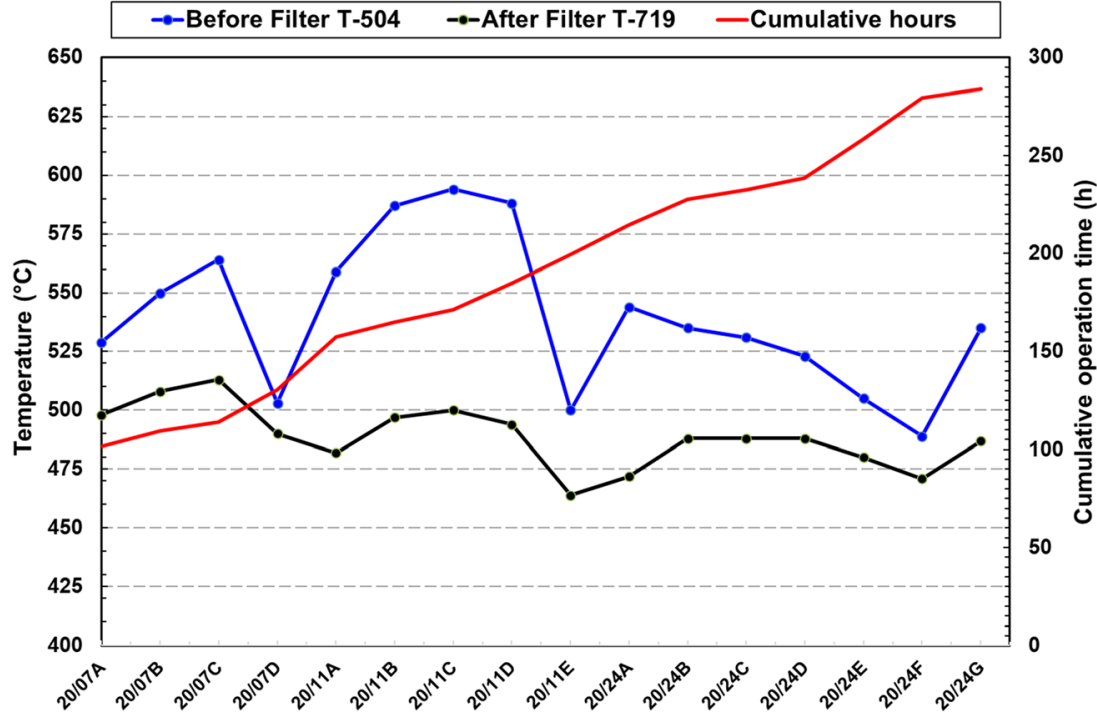

beginning of the first set point 20/07A, despite additive feeding. However, when the pulsing pressure was raised from 0.6 to $0.8 \mathrm{MPa}$, this tendency was stopped and gradually the pressure drop decreased to a stable and lower level. Between set points $\mathrm{C}$ and $\mathrm{D}$, the bed height was once again raised by feeding more biomass than was consumed by the gasification and combustion reactions, and this temporarily increased the filter pressure drop. In the test run, SXB 20/11, the pressure drop of the filter was rather stable at all set points and increasing tendencies were met only during periods when the bed inventory was increased (before the first set point and between set points D and E). It can be concluded that in the tests realized with the original division plate separating the two gasifier stages, the filter could be operated with a stable pressure drop. Feeding a mixture of dolomite and sand into the raw gas before the filter helped cake build-up and protected the elements from tar/soot blinding.

In the last test run, SXB 20/24, realized with a more open division plate in the gasifier, the filter operation was less stable. During the first three set points, the pressure drop was quite constant and stayed at the same level as in previous test runs, but then it started to increase slowly but steadily despite the additive feeding. The secondary zone did not operate as efficiently as in the case of the original division plate. Previous experiences have indicated that filtration-related problems correlate with concentrations of high-molecular-weight tars. Figure 11 shows the measured total concentrations of tars, the molecular weight of which is higher than that of naphthalene. Despite the large scatter in the data, these results show that heavy tar contents were generally higher in the last test run than at the previous test runs realized with the original division plate.

Further development is needed to improve the contact between the updraft raw gas and the catalyst elements of the secondary stage. Feeding porous charcoal-type additives into the filter instead of hard sand and dolomite particles as well as dust recycling could also assist in avoiding the formation of a sticky dust cake, even with slightly higher raw gas tar contents. The used face velocities were also rather high, and lower pressure drops and easier cake removal during pulse cleaning could be expected by increasing the number of filter elements or the length or diameter of individual filter cartridges.

\subsection{The effect of the reformer on the performance of the gasification process}

Detailed results for the reformer research have already been partly presented in [26] and will be further published in another paper focused on reforming and final gas cleaning results (in preparation by Frilund, C, Kurkela, E, Hiltunen I). To illustrate the great importance of the reformer on the overall efficiency of syngas production, the key results for the reformer are presented in Table 5 and further analyzed in Figs. 12 and 13.

Figure 12 shows the dry gas composition before and after the reformer calculated as nitrogen-free gas, since more nitrogen was fed into the process at the pilot plant than will be needed at target industrial applications. It can be noted that at all set points, the concentrations of light hydrocarbon gases, benzene, and tars are decreasing and the hydrogen concentration is increasing in the reformer. It should be taken into account that the total volume flow of gas is increasing in the reformer at these set points by $26-54 \%$ due to feeding of reaction gas to both reformer stages and due to reforming of tars and hydrocarbon gases. At set point 20/11A, the gasifier was operated with steam and oxygen, while at set point 20/ $11 \mathrm{~B}$ roughly half of the primary steam was replaced by $\mathrm{CO}_{2}$. This resulted in a higher $\mathrm{CO}$ concentration and a lower $\mathrm{H}_{2}$ concentration, as the shift reaction pushes the composition towards equilibrium. 
Fig. 10 Pressure drops of the filter and the reformer in the test runs of 2020
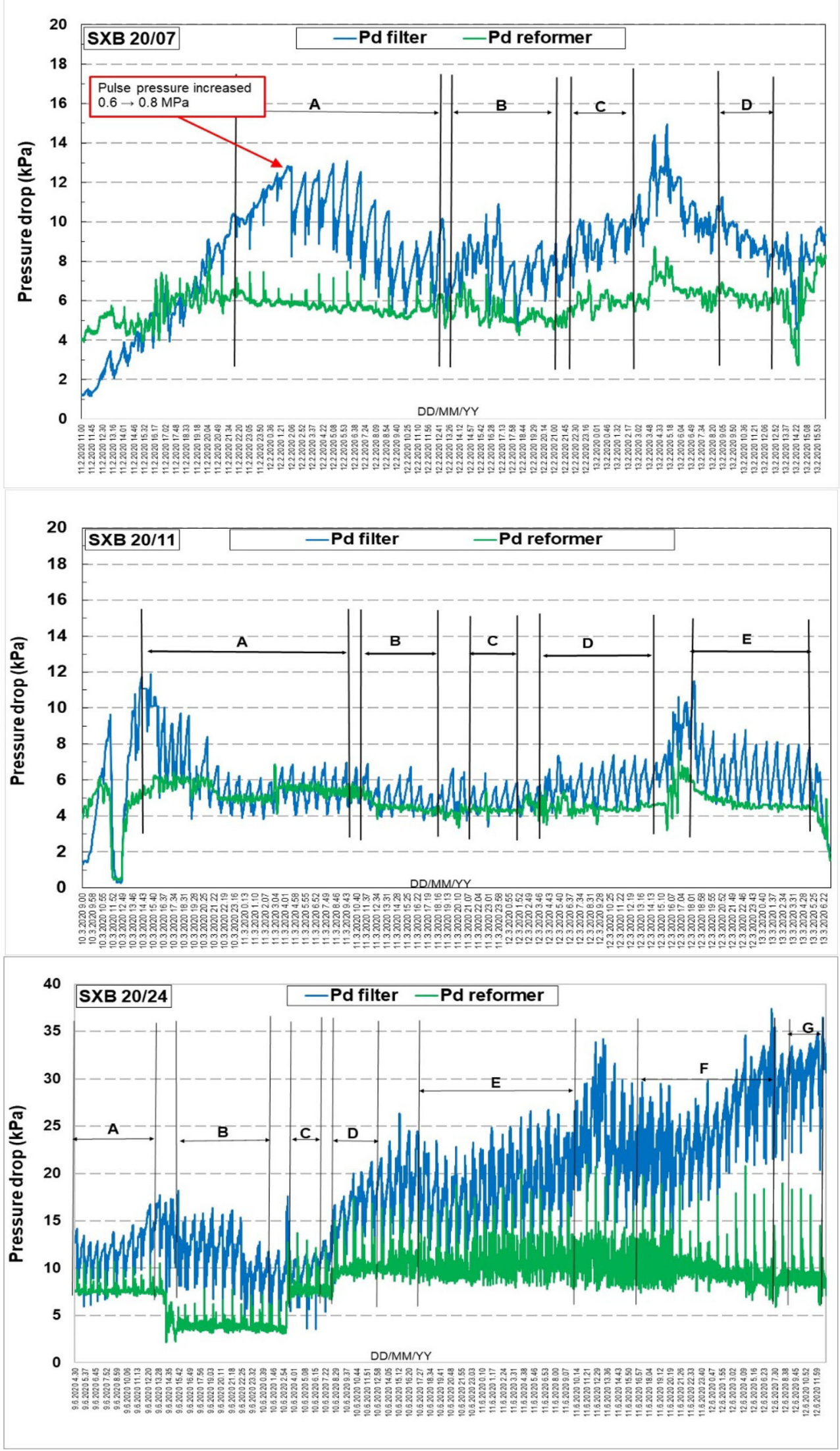
Fig. 11 Concentrations of heavy tars measured from the raw gas after the filter

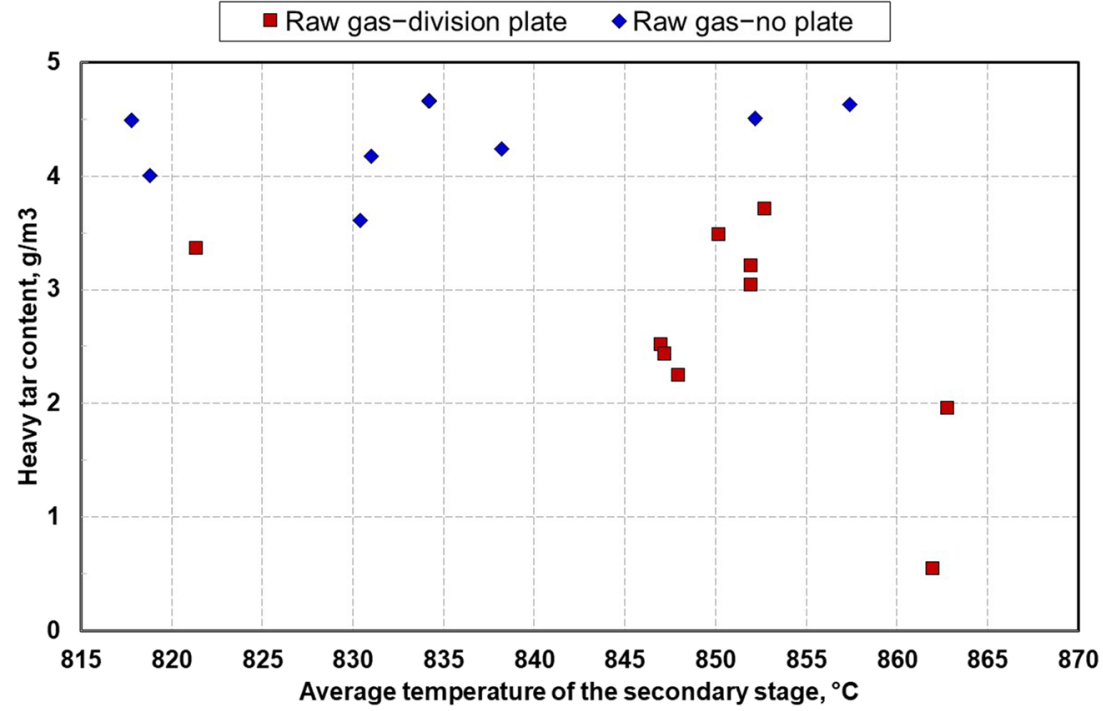

Figure 13 shows the calculated efficiencies from input biomass energy to different gas components and tars. These results are presented for set point $20 / 24 \mathrm{D}$, realized with clean wood, and set point 20/24E, carried out with sunflower husks. All streams are calculated using lower heating values. It can be noted that the hydrocarbon gases and tars represent roughly

Table 5 Main operating conditions of the reformer at selected set points

\begin{tabular}{|c|c|c|c|c|c|c|c|c|c|c|}
\hline Set point & $19 / 34 \mathrm{G}$ & $19 / 34 \mathrm{H}$ & 20/07D & $20 / 11 \mathrm{~A} 2$ & 20/11B & 20/24D & $20 / 24 \mathrm{~F} 1$ & 20/11D & $20 / 11 \mathrm{E}$ & 20/24E2 \\
\hline Feedstock & $\mathrm{FRW}+\mathrm{K}$ & $\mathrm{FRW}+\mathrm{K}$ & WCH & WP & WP & WP & WP & $\mathrm{BP}$ & SFP & SFP \\
\hline \multicolumn{11}{|l|}{ Inlet raw gas flow rate, $\mathrm{g} / \mathrm{s}$} \\
\hline $\mathrm{O}_{2}$ to stage 1 & 1.3 & 1.03 & 1.49 & 1.4 & 1.31 & 1.8 & 2.22 & 1.21 & 1.23 & 2.03 \\
\hline $\mathrm{N}_{2}$ to stage 1 & 4.30 & 3.87 & 2.86 & 2.2 & 2.2 & 3.1 & 3.65 & 2 & 1.98 & 3.5 \\
\hline $\mathrm{O}_{2}$ to stage 2 & 0.73 & 0.60 & 0.27 & 0.37 & 0.3 & 0.45 & 0.38 & 0.39 & 0.4 & 0.51 \\
\hline $\mathrm{N}_{2}$ to stage 2 & 3.98 & 2.68 & 0.57 & 0.97 & 0.97 & 1.17 & 1.2 & 0.77 & 0.77 & 1.07 \\
\hline \multicolumn{11}{|l|}{ Reformer temperatures, ${ }^{\circ} \mathrm{C}$} \\
\hline Inlet of stage 1 & 546 & 543 & 519 & 512 & 520 & 524 & 515 & 524 & 494 & 518 \\
\hline Average, stage 1 & 744 & 724 & 847 & 856 & 859 & 733 & 755 & 877 & 874 & 754 \\
\hline Outlet stage 1 & 818 & 799 & 782 & 752 & 757 & 765 & 802 & 770 & 769 & 803 \\
\hline Average, stage 2 & 921 & 900 & 845 & 876 & 867 & 902 & 920 & 917 & 913 & 934 \\
\hline Outlet stage 2 & 918 & 892 & 764 & 751 & 755 & 808 & 836 & 781 & 786 & 836 \\
\hline \multicolumn{11}{|l|}{ Pressure drops, $\mathrm{kPa}$} \\
\hline Stage 1 & 1.0 & 0.8 & 3.6 & 3.1 & 2.5 & 4.0 & 4.1 & 2.6 & 2.6 & 4.3 \\
\hline Stage 2 & 1.2 & 1.0 & 2.5 & 2.3 & 1.9 & 6.0 & 5.8 & 2.0 & 2.0 & 6.6 \\
\hline \multicolumn{11}{|c|}{ Gas after reformer by volume, dry basis } \\
\hline $\mathrm{CO}(\%)$ & 7.8 & 11.0 & 13.3 & 14.9 & 20.5 & 14.8 & 16.9 & 14.3 & 12.9 & 16.0 \\
\hline $\mathrm{CO}_{2}(\%)$ & 22.6 & 29.5 & 27.1 & 28.1 & 34.0 & 28.6 & 25.7 & 31.3 & 32.2 & 26.5 \\
\hline $\mathrm{H}_{2}(\%)$ & 16.0 & 13.9 & 26.9 & 30.7 & 24.5 & 28.8 & 27.3 & 26.7 & 26.2 & 26.8 \\
\hline $\mathrm{N}_{2}(\%)$ & 51.5 & 42.9 & 31.9 & 25.2 & 20.2 & 27.7 & 29.7 & 26.2 & 25.7 & 28.8 \\
\hline $\mathrm{CH}_{4}(\%)$ & 2.1 & 2.6 & 0.7 & 1.1 & 0.8 & 0.1 & 0.4 & 1.5 & 3.1 & 1.8 \\
\hline $\mathrm{C}_{2} \mathrm{H}_{2}(\%)$ & 0.0 & 0.0 & 0.0 & 0.00 & 0.00 & 0.00 & 0.00 & 0.00 & 0.00 & 0.00 \\
\hline $\mathrm{C}_{2} \mathrm{H}_{4}(\%)$ & 0.1 & 0.1 & 0.1 & 0.00 & 0.00 & 0.00 & 0.00 & 0.00 & 0.00 & 0.00 \\
\hline $\mathrm{C}_{2} \mathrm{H}_{6}(\%)$ & 0.01 & 0.01 & 0.01 & 0.00 & 0.00 & 0.00 & 0.00 & 0.00 & 0.00 & 0.00 \\
\hline $\mathrm{C}_{3}-\mathrm{C}_{5} \mathrm{H}_{\mathrm{y}}(\%)$ & 0.00 & 0.00 & 0.00 & 0.00 & 0.00 & 0.00 & 0.00 & 0.00 & 0.00 & 0.00 \\
\hline Benzene, $\mathrm{g} / \mathrm{m}^{3}$ in dry gas & 316 & 1623 & 160 & 491 & 292 & 215 & 229 & 1340 & 4574 & 3942 \\
\hline
\end{tabular}


Table 5 (continued)

\begin{tabular}{|c|c|c|c|c|c|c|c|c|c|c|}
\hline Set point & 19/34G & 19/34H & 20/07D & $20 / 11 \mathrm{~A} 2$ & 20/11B & 20/24D & $20 / 24 \mathrm{~F} 1$ & 20/11D & $20 / 11 \mathrm{E}$ & 20/24E2 \\
\hline Tars, $\mathrm{mg} / \mathrm{m}^{3}$ in dry gas & 14 & 189 & 0 & 2.7 & 1.0 & 2.9 & 1.1 & 6.0 & 204 & 254 \\
\hline $\mathrm{NH}_{3}, \mathrm{mg} / \mathrm{m}^{3}$ in dry gas & nd & nd & 513 & 269 & 244 & 0,0 & 0,0 & 1217 & 2490 & 1687 \\
\hline Wet gas after reformer, $\mathrm{m}^{3} / \mathrm{h}$ & 134.0 & 108.6 & 139.0 & 133.1 & 117.8 & 144.9 & 133.9 & 118.5 & 119.6 & 142.7 \\
\hline \multicolumn{11}{|l|}{ Wet gas $\mathrm{H}_{2} \mathrm{O}$ content, by volume } \\
\hline From tar samples (\%) & 34.3 & 25.3 & 28.1 & 29.3 & 23.2 & 34.0 & 33.3 & 32.0 & 35.9 & 35.7 \\
\hline From H-balance (\%) & 35.1 & 24.2 & 33.8 & 30.3 & 23.5 & 30.5 & 29.3 & 34.1 & 34.6 & 30.9 \\
\hline \multicolumn{11}{|l|}{ Calculated performances } \\
\hline GHSV — stage 1 (STP)a & 3913 & 3198 & 3751 & 3434 & 3048 & 3800 & 3492 & 3141 & 3227 & 3890 \\
\hline GHSV — stage 1 (actual)b & 6233 & 4988 & 6479 & 5896 & 5236 & 7760 & 7631 & 5512 & 5794 & 8499 \\
\hline GHSV — stage $2(\mathrm{STP}) \mathrm{c}$ & 5036 & 4080 & 3658 & 3501 & 3100 & 4764 & 4403 & 3117 & 3147 & 4692 \\
\hline GHSV — stage 1 (actual)d & 9410 & 7483 & 6304 & 6117 & 5361 & 11,366 & 11,172 & 5660 & 5843 & 12,042 \\
\hline C-balance closure (out/in) & 0.93 & 0.93 & 0.84 & 1.03 & 0.98 & 1.03 & 0.98 & 0.96 & 1.02 & 0.93 \\
\hline O-balance closure (out/in) & 1.01 & 1.02 & 1.00 & 1.00 & 1.00 & 1.01 & 0.97 & 1.00 & 1.00 & 0.99 \\
\hline Methane conversion, $\%$ & 53.4 & 43.8 & 84.5 & 75.7 & 82.3 & 97.8 & 91.9 & 67.0 & 44.1 & 63.5 \\
\hline $\mathrm{C}_{2}-\mathrm{C}_{5} \mathrm{H}_{\mathrm{y}}$ conversion, $\%$ & 90.7 & 91.4 & 88.1 & 100 & 100 & 100 & 100 & 100 & 100 & 100 \\
\hline Benzene conversion, $\%$ & 95.6 & 82.1 & 96.6 & 93.5 & 96.2 & 97.4 & 97.4 & 86.1 & 57.5 & 58.8 \\
\hline Tar conversion, $\%$ & 99.6 & 97.1 & 100.0 & 99.9 & 100.0 & 100 & 100 & 99.9 & 96.7 & 97.1 \\
\hline K-shift, from wet gas analysis & 0.9 & 1.2 & 1.1 & 1.3 & 1.3 & 1.3 & 1.0 & 1.1 & 1.2 & 1.0 \\
\hline K-shift calc. at reformer exit $\mathrm{T}$ & 0.7 & 0.8 & 1.2 & 1.3 & 1.2 & 1.0 & 0.9 & 1.1 & 1.1 & 0.9 \\
\hline $\mathrm{H}_{2} / \mathrm{CO}$ molar ratio & 2.05 & 1.26 & 2.03 & 2.06 & 1.19 & 1.95 & 1.61 & 1.86 & 2.03 & 1.67 \\
\hline \multicolumn{11}{|l|}{ Syngas $\left(\mathrm{CO}+\mathrm{H}_{2}\right)$ yield, $\mathrm{mol} / \mathrm{kg}_{\text {daf }}$} \\
\hline Before reformer & 24.2 & 22.7 & 24.5 & 28.5 & 29.4 & 27.2 & 26.1 & 26.6 & 27.3 & 26.8 \\
\hline After reformer & 29.4 & 29.0 & 35.8 & 48.7 & 46.7 & 49.6 & 49.9 & 42.8 & 40.0 & 42.9 \\
\hline
\end{tabular}

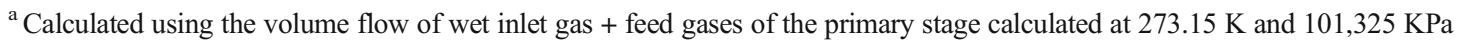

${ }^{\mathrm{b}}$ Calculated using the volume flow of wet inlet gas + feed gases of the primary stage calculated at actual average temperature of bed 1 and at the actual pressure of gas in the inlet of the reformer

${ }^{\mathrm{c}}$ Calculated using the volume of the syngas after the reformer calculated at $273.15 \mathrm{~K}$ and $101,325 \mathrm{KPa}$

${ }^{\mathrm{d}}$ Calculated using the volume of the syngas after the reformer calculated at the actual average temperature of bed 2 and at the pressure of gas in the outlet of the reformer

half of the energy content of raw gas. In the reformer, these compounds are reacting with steam and $\mathrm{CO}_{2}$ resulting in significantly increased efficiency to targeted syngas components, hydrogen, and carbon monoxide. The decreased catalyst activity caused by sulfur can also be observed in the energy conversion efficiencies. Better reformer performance, even with sulfur-containing biomass, can be achieved by increasing the number of catalyst beds from two to three and by operating the reformer at higher temperatures.

\section{Conclusions and further R\&D needs}

A new gasification process has been developed and tested at the pilot scale for converting biomass residues to synthesis gas. The key processing steps of this process consist of a pressurized staged fixed-bed gasifier, hot gas filtration, and catalytic reforming of tars and hydrocarbon gases. These unit operations have been developed to technology readiness level TRL 5 and the process has been successfully used to produce gas for ultrapurification and the Fischer-Tropsch synthesis unit tested in a smaller slipstream of the pilot plant. This process is considered to be ready for follow-on industrial demonstration before entering into the targeted commercial scale of 5-50 MW feedstock input. In the FlexCHX project, a preliminary design based on single gasifier line was made for a 50-MW plant as well as for a 5-MW demonstration unit. This intermediate demonstration plant is needed especially for determining the long-term phenomena, such as stability of bottom ash removal, the durability of the filters, and the lifetime of reformer catalysts. The realized oneweek-long experiments already verified that the plant could be operated without severe deposit formation or clogging problems and the activity of the reformer remained stable. The developed gasifier is a combination of the primary counter-current fixed-bed and the secondary gasification stage, where most of the updraft tars are decomposed and the gas temperature is raised to 800 $870{ }^{\circ} \mathrm{C}$. The resulting gas can be cleaned using similar gas cooling, filtration, reforming, and final gas cleaning systems as 
Fig. 12 The effect of the reformer on syngas composition

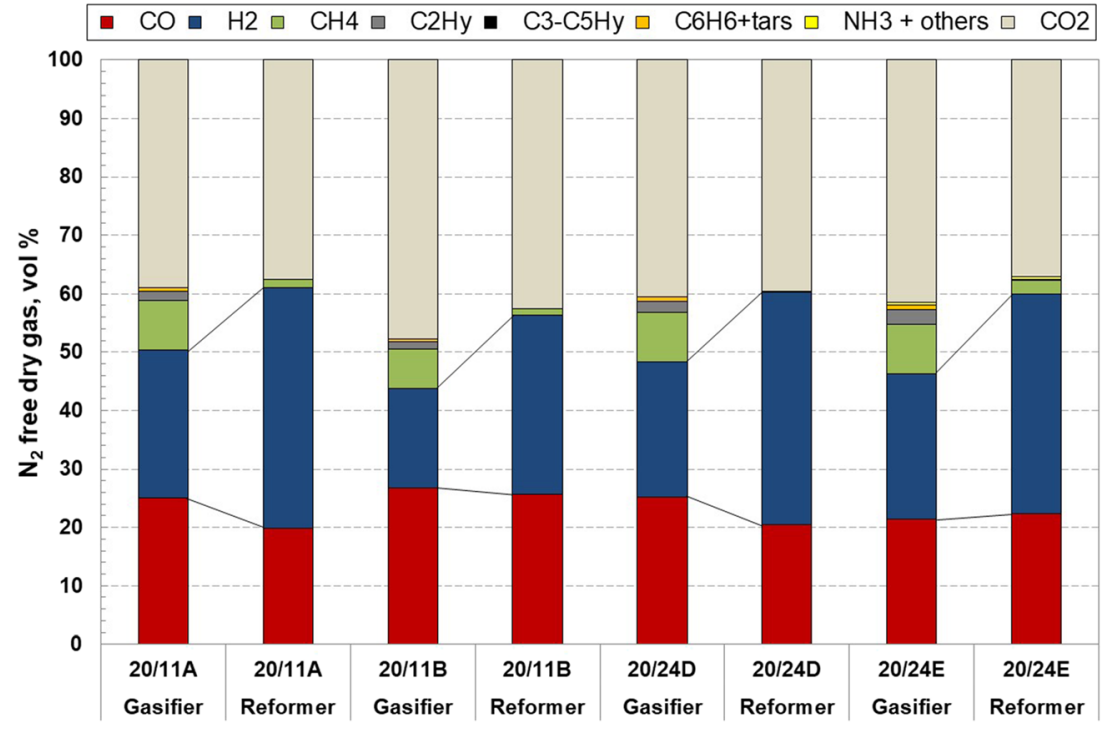

previously developed for fluidized-bed gasifiers. However, as the particulate content of raw gas is very low, additional sorbent feeding and/or dust circulation is needed to achieve surface filtration and stable build-up and removal of dust cake on the filter elements. The main gas constituents, $\mathrm{CO}, \mathrm{H}_{2} \mathrm{O}, \mathrm{CO}_{2}$, and $\mathrm{H}_{2}$, approach the equilibrium of water gas shift reaction, which is essential for realizing the basic idea of the FlexCHX process. In this process, biomass gasification can be boosted by electrolysis hydrogen when low-cost electricity is available, while the same process can be used with biomass alone when electricity prices are high. In the electrolysis-assisted operation mode, $\mathrm{CO}_{2}$ separated in the final gas cleaning unit is recycled back to the gasifier replacing the gasification steam. This pushes the shiftequilibrium after the reformer towards high concentrations of carbon monoxide, creating a space for additional hydrogen.

The pilot tests verified that the two-stage fixed-bed gasifier operated according to expectations, but several items for further improvement were also identified. The distribution of the tarcontaining cool gas from the primary to the secondary stage needs further optimization. Furthermore, secondary stage designs incorporating more intensive contact of the gas and the catalystcontaining secondary gas distribution system can be considered because there were no signs of dust accumulation in these tests realized with a rather open catalyst arrangement. This can be expected to result in lower tar contents and improved filter operation. The robust metal filters operated reliably and without any signs of dust penetration or filter breakages. Further development topics include increased filter dimensions, improved pulse cleaning systems, and operation at higher temperatures than were used in these tests. Excellent reformer performance was achieved at an outlet temperature of $750-800{ }^{\circ} \mathrm{C}$ with woody biomass residues when precious metal development catalysts were used. Almost as high conversion efficiencies could be achieved with commercial nickel catalysts by increasing the operating
Fig. 13 The effect of the reformer on the biomass-to-syngas energy conversion efficiency (LHV basis)

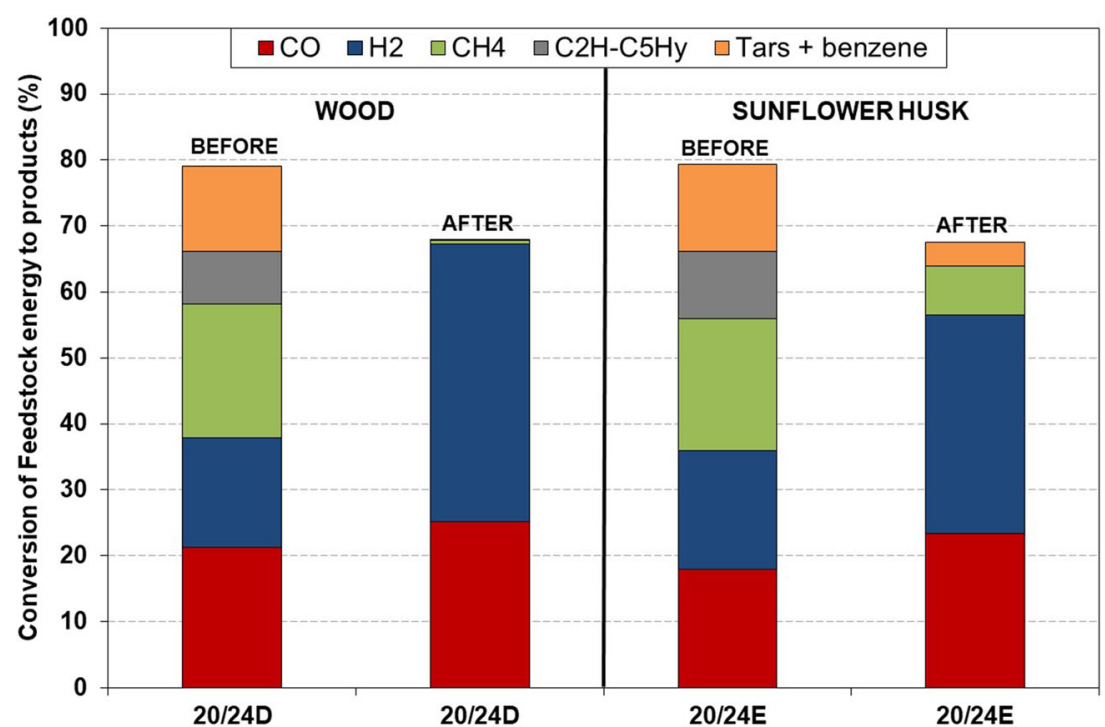


temperatures so that the outlet temperature was $900{ }^{\circ} \mathrm{C}$. The conversion efficiencies for methane and benzene were lower with the sunflower husks, which contained more sulfur. With this type of feedstock, the number of reformer stages should be increased from two to three and the reformer should be operated at higher temperatures.

Acknowledgements The valuable contributions of the technical and analytical staff of VTT to the construction, operation, and performing measurements at the SXB pilot plant are greatly appreciated. We want to especially thank Mr. Harri Luomala for the mechanical design of the plant and for leading the technical staff during modification and operation activities. The assistance received from other project partners, namely Enerstena, Lithuanian Energy Institute (LEI), and catalyst supplier Johnson Matthew (JM) is greatly acknowledged. Enerstena and LEI participated in the test campaigns and JM supplied the precious metal catalysts for the reformer testing.

Code availability Not applicable.

Author contribution Authors Esa Kurkela and Ilkka Hiltunen invented the new gasifier and led the design, construction, and operation activities at the pilot plant. Minna Kurkela processed the experimental data and prepared the tables and figures of the paper. Esa Kurkela and Minna Kurkela prepared the manuscript. All authors discussed the results and commented the manuscript.

Funding Open access funding provided by Technical Research Centre of Finland (VTT). This work has been carried out as part of the FlexCHX project, which has received funding from the European Union's Horizon 2020 Research and Innovation Programme under Grant Agreement No. 763919.

Data availability Full.

\section{Declarations}

Conflict of interest The authors declare no competing interests.

Open Access This article is licensed under a Creative Commons Attribution 4.0 International License, which permits use, sharing, adaptation, distribution and reproduction in any medium or format, as long as you give appropriate credit to the original author(s) and the source, provide a link to the Creative Commons licence, and indicate if changes were made. The images or other third party material in this article are included in the article's Creative Commons licence, unless indicated otherwise in a credit line to the material. If material is not included in the article's Creative Commons licence and your intended use is not permitted by statutory regulation or exceeds the permitted use, you will need to obtain permission directly from the copyright holder. To view a copy of this licence, visit http://creativecommons.org/licenses/by/4.0/.

\section{References}

1. Maniatis K, Landälv I, van den Heuvel E,Kalligeros S (2017) Final report - building up the future: Sub group on Advanced Biofuels Sustainable Transport Forum. European Commission, Brussels
2. Rauch R, Hrbek J, Hofbauer H (2014) Biomass gasification for synthesis gas production and applications of the syngas. Wiley Interdisciplinary Reviews: Energy and Environment WIREs Energy Environ 3:343-362. https://doi.org/10.1002/wene.97

3. Hofbauer H (2019) Large scale biomass gasification for electricity and fuels, in energy from organic materials (biomass). Encyclopedia of sustainability science and technology series. Springer, New York

4. Jafri Y, Furusjö E, Kirtania K, Gebart R (2016) Performance of a pilot-scale entrained-flow black liquor gasifier. Energy Fuel 30(4): 3175-3185. https://doi.org/10.1021/acs.energyfuels.6b00349

5. Svoboda K, Pohorely M, Hartman M, Martinec J (2009) Pretreatment and feeding of biomass for pressurized entrained flow gasification. Fuel Process Technol 90(5):629-635. https://doi.org/ 10.1016/j.fuproc.2008.12.005

6. Dahmen N, Abeln J, Eberhard M, Kolb T, Leibold H, Sauer J, Stapf D, Zimmerlin B (2017) The bioliq process for producing synthetic transportation fuels. WIREs Energy Environ 6:e236. https://doi. org/10.1002/wene.236C

7. Van der Drift A, Boerrigter H, Coda B, Cieplik MK, Hemmes K (2004) Entrained flow gasification of biomass. Ash behaviour, feeding issues, system analyses, ECN-C-04-039, Netherlands

8. Ranta J (1996) Characteristics and utilisation of high-temperature (HTHP) filter dusts from PFB gasification of biomass. In: Power production from biomass II with special emphasis on gasification and pyrolysis R\&DD, Espoo

9. Gómez-Barea A, Vilches L, Leiva C et al (2009) Plant optimisation and ash recycling in fluidised bed waste gasification. Chem Eng J 146(2):227-236. https://doi.org/10.1016/j.cej.2008.05.039

10. Moilanen A (2006) Thermogravimetric characterisations of biomass and waste for gasification processes. VTT Technical Research Centre of Finland, Espoo, PhD Thesis

11. Kurkela E, Kurkela M, Moilanen A (2006) Fluidised-bed gasification of high-alkali biomass fuels. In: A. V. Bridgwater, \& D. G. B. Boocock (Eds.), Science in Thermal and Chemical Biomass Conversion 1:662-676

12. Kurkela E, Kurkela M, Hiltunen I (2016) Steam-oxygen gasification of forest residues and bark followed by hot gas filtration and catalytic reforming of tars: results of an extended time test. Fuel Process Technol 141(Part 1):148-158. https://doi.org/10.1016/j. fuproc.2015.06.005

13. Jokela V (2011) Wood based BTL diesel development in 20072011 by NSE Biofuels Oy. In: IEA Bioenergy Task 33 Workshop, Piteå

14. Voegele E (2012) Neste Oil and Stora Enso shelve plans for renewable diesel plant. Biomass Magazine, Grand Forks, USA, http:// biomassmagazine.com/articles/7962/neste-oil-stora-enso-shelveplans-for-renewable-diesel-plant Accessed 042021

15. Kurkela E, Kurkela M, Tuomi S, Frilund C, Hiltunen I (2019), Efficient use of biomass residues for combined production of transport fuels and heat, VTT Technical Research Centre of Finland, VTT Technology No. 347 https://doi.org/10.32040/2242-122X. 2019.T347

16. Kurkela E, Tuomi S, Kurkela M, Hiltunen I (2019) Flexible hybrid process for combined production of heat, power and renewable feedstock for refineries. In: 27th European Biomass Conference and Exhibition EUBCE 2019, Lisbon

17. Sansaniwal S, Pal K, Rosen M, Tyagi S (2017) Recent advances in the development of biomass gasification technology: a comprehensive review. Renew Sust Energ Rev 72:363-384. https://doi.org/10. 1016/j.rser.2017.01.038

18. Chopra S, Jain A (2007) A review of fixed bed gasification systems for biomass. Agricultural Engineering International: the CIGR Ejournal, invited overview, IX(5) 
19. Reed T, Das A (1988) Handbook of biomass downdraft gasifier engine systems, Biomass Energy Foundation, Golden Colorado https://www.nrel.gov/docs/legosti/old/3022.pdf Accessed 042021

20. Reed TB, Levie B, Graboski MS (1987) Fundamentals, development and scaleup of the air-oxygen stratified downdraft gasifier. Report SERI/PR-234-2571, Golden Colorado https://www.nrel. gov/docs/legosti/old/2571.pdf Accessed 042021

21. Kurkela E, Ståhlberg P, Simell P, Leppälahti J (1989) Updraft gasification of peat and biomass. Biomass 19(1-2):37-46

22. van Dyk J, Keyser M, Coertzen M (2006) Syngas production from south African coal sources using Sasol-Lurgi gasifiers. Int J Coal Geol 65(3-4):243-253. https://doi.org/10.1016/j.coal.2005.05.007

23. Kurkela E, Simell P, Ståhlberg P, Berna G, Barbagli F, Haavisto I (2000) Development of novel fixed-bed gasification for biomass residues and agrobiofuels. VTT - Research Notes, no. 2059, VTT Technical Research Centre of Finland, Espoo. http://www.vtt.fi/inf/ pdf/tiedotteet/2000/T2059.pdf Accessed 042021

24. Simell P, Bredenberg J (1990) Catalytic purification of tarry fuel gas. Fuel 69(10):1219-1225

25. Kurkela E, Kurkela M, Hiltunen I, Frilund C (2021) Production of synthesis gas from biomass residues by staged fixed-bed gasification - results from pilot test campaigns. Chem Eng Trans 86(6) (in press)

26. Kurkela E, Kurkela M, Frilund C, Hiltunen I, Rollins B, Steele A (2021) Flexible hybrid process for combined production of heat, power and renewable feedstock for refineries. Johnson Matthey Technology Review 65(2):333-345. https://doi.org/10.1595/ 205651321X16013744201583

27. Kurkela E, Hiltunen I (2016) Method for gasifying raw material and a gaseous product. Patent No WO2016/075362 A1

28. Kurkela E, Hiltunen I (2019) An apparatus, method and use for purifying gas from tar-like impurities. Finnish Patent Appl. PC19041FI

29. Kurkela E, Kurkela M, Hiltunen I (2014) The effects of wood particle size and different process variables on the performance of steam-oxygen blown circulating fluidized-bed gasifier. Environmental Progress and Sustainable Energy 33(3):681-687. https://doi.org/10.1002/ep.12003

30. Tuomi S, Kurkela E, Kurkela M, Hiltunen I, Balzer H, Wierhake A (2019) Novel sintered metal filter elements: performance evaluation in biomass gasification conditions. In: FILTECH 2019 Conference proceedings, Cologne

31. Tuomi S, Kurkela E, Simell P, Reinikainen M (2015) Behaviour of tars on the filter in high temperature filtration of biomass-based gasification gas. Fuel 139:220-231. https://doi.org/10.1016/j.fuel. 2014.08.051

32. Frilund C, Tuomi S, Kurkela E, Simell P (2021) Small-to-mediumscale deep syngas purification: biomas-to-liquids multicontaminant removal demonstration. Biomass Bioenergy 148:106031. https:// doi.org/10.1016/j.biombioe.2021.106031

33. Kurkela E, Ståhlberg P, Laatikainen J (1993) Pressurized fluidizedbed gasification experiments with wood, peat and coal at VTT in 1991-1992. Part 1. Test facilities and gasification experiments with sawdust. VTT Technical Research Centre of Finland, VTT Publications 161, Espoo

34. European Tar Protocol TC BT/TF 143 (2004) Biomass gasification - tar and particles in product gases -sampling and analysis, Brussels, Belgium http://www.eeci.net/results/pdf/CEN-Tar-Standard-draftversion-2_1-new-template-version-05-11-04.pdf

35. Hannula I, Kurkela E (2011) A parametric modelling study for pressurised steam/O2-blown fluidised-bed gasification of wood with catalytic reforming. Biomass Bioenergy 38:58-67. https:// doi.org/10.1016/j.biombioe.2011.02.045

36. Rhinehart R, Felder R, Ferrell J (1987) Dynamic modeling of a pilot-scale fluidized-bed coal gasification reactor. Ind Eng Chem Res 26(4):738-745. https://doi.org/10.1021/ie00064a019

37. Pfeiffer C, Koppatz S, Hofbauer H (2011) Steam gasification of various feedstocks at the dual fluidised bed gasifier: impacts of operation conditions and bed materials. Biomass Conversion and Biorefining 1:39-53. https://doi.org/10.1007/s13399-011-0007-1

38. Karl J, Pröll T (2018) Steam gasification of biomass in dual fluidized bed gasifiers: a review. Renew Sust Energ Rev 98:64-78. https://doi.org/10.1016/j.rser.2018.09.010

39. Abdoulmoumine N, Adhikari S, Kulkarni A, Chattanathan S (2015) A review on biomass gasification syngas cleanup. Appl Energy 155:294-307. https://doi.org/10.1016/j.apenergy.2015.05.095

40. Leppälahti J (1998) Behaviour of fuel-bound nitrogen in gasification and in high-temperature NH3 removal processes. VTT Technical Research Centre of Finland, Espoo, PhD Thesis

41. Mojtahedi W, Backman R (1989) The state of sodium and potassium in the pressurized fluidized-bed combustion and gasification of peat. Journal of the Institute of Energy 62(453):189-196

Publisher's Note Springer Nature remains neutral with regard to jurisdictional claims in published maps and institutional affiliations. 